\title{
A Review: Ion Transport of Two-Dimensional Materials in Novel Technologies from Macro to Nanoscopic Perspectives
}

\author{
Nawapong Unsuree ${ }^{1, *}$, Sorasak Phanphak ${ }^{2, *}$, Pongthep Prajongtat ${ }^{3}$, Aritsa Bunpheng ${ }^{4}$, Kulpavee Jitapunkul ${ }^{5}\left({ }^{\circ}\right.$, \\ Pornpis Kongputhon ${ }^{6}$, Pannaree Srinoi ${ }^{4}\left(\mathbb{D}\right.$, Pawin Iamprasertkun $5,6, * \mathbb{C}$ and Wisit Hirunpinyopas ${ }^{4, *(1)}$
}

1 Department of Physics, Academic Division, Chulachomklao Royal Military Academy, Nakhon Nayok 26001, Thailand

2 Department of Physics, Faculty of Science, Kasetsart University, Bangkok 10900, Thailand

3 Department of Materials Science, Faculty of Science, Kasetsart University, Bangkok 10900, Thailand; fscipop@ku.ac.th

4 Department of Chemistry and Centre of Excellence for Innovation in Chemistry, Faculty of Science, Kasetsart University, Bangkok 10900, Thailand; aritsa.b@ku.th (A.B.); pannaree.sr@ku.ac.th (P.S.)

5 School of Bio-Chemical Engineering and Technology, Sirindhorn International Institute of Technology, Thammasat University, Pathum Thani 12120, Thailand; kulpavee.work@gmail.com

6 Department of Applied Physics, Faculty of Sciences and Liberal Arts, Rajamangala University of Technology Isan, Nakhon Ratchasima 30000, Thailand; pornpis.k@rmuti.ac.th

* Correspondence: nawapong.un@crma.ac.th (N.U.); sorasak.pha@ku.ac.th (S.P.); pawin.ia@rmuti.ac.th (P.I.); wisit.hi@ku.ac.th (W.H.)

check for updates

Citation: Unsuree, N.; Phanphak, S.; Prajongtat, P.; Bunpheng, A.;

Jitapunkul, K.; Kongputhon, P.; Srinoi,

P.; Iamprasertkun, P.; Hirunpinyopas,

W. A Review: Ion Transport of

Two-Dimensional Materials in Novel Technologies from Macro to

Nanoscopic Perspectives. Energies

2021, 14, 5819. https://doi.org/

$10.3390 /$ en14185819

Academic Editor: Nick Papanikolaou

Received: 10 August 2021

Accepted: 9 September 2021

Published: 14 September 2021

Publisher's Note: MDPI stays neutral with regard to jurisdictional claims in published maps and institutional affiliations.

Copyright: (c) 2021 by the authors. Licensee MDPI, Basel, Switzerland. This article is an open access article distributed under the terms and conditions of the Creative Commons Attribution (CC BY) license (https:/ / creativecommons.org/licenses/by/ $4.0 /)$.
Abstract: Ion transport is a significant concept that underlies a variety of technologies including membrane technology, energy storages, optical, chemical, and biological sensors and ion-mobility exploration techniques. These applications are based on the concepts of capacitance and ion transport, so a prior understanding of capacitance and ion transport phenomena is crucial. In this review, the principles of capacitance and ion transport are described from a theoretical and practical point of view. The review covers the concepts of Helmholtz capacitance, diffuse layer capacitance and space charge capacitance, which is also referred to as quantum capacitance in low-dimensional materials. These concepts are attributed to applications in the electrochemical technologies such as energy storage and excitable ion sieving in membranes. This review also focuses on the characteristic role of channel heights (from micrometer to angstrom scales) in ion transport. Ion transport technologies can also be used in newer applications including biological sensors and multifunctional microsupercapacitors. This review improves our understanding of ion transport phenomena and demonstrates various applications that is applicable of the continued development in the technologies described.

Keywords: ion transport; capacitance; 2D materials; multifunctional energy storages; stimulus-responsive microsupercapacitor; fluorescence imaging; molecular transport

\section{Introduction}

Ion transport is one of the basic principles of the development of various different technologies that can improve the quality of our lives, such as the ever-growing importance of clean and sustainable energy, the reduction of water scarcity and even the improvement of fundamental medical application knowledge. Ion transport can be defined as the movement of charged ions from one position to another in ion electrolyte solutions within both organic (living cells) and inorganic (polymer materials) systems. Ion transport can be encouraged through various mechanisms such as electrochemical diffusion, ion active transport requiring external energy or bulk transport for the conversion of adenosine triphosphate (ATP) and energy consumption in biological functions [1]. This can be clearly seen in the sodium/potassium $\left(\mathrm{Na}^{+} / \mathrm{K}^{+}\right)$ions exchange pump, which is an important ion transportation mechanism that generally occurs in living cell membranes such as plant and animal cells [1,2]. For example, the electric eel possesses a system which demonstrates 
the evolution of biological membranes under ionic concentration gradients that provide ion transport for power generation. By combining a number of membranes with highly packed selectively ionic channels, electric eels can produce a strong current density which can discharge up to 600 Volts [3]. Ion transportation can be used as a potential way of understanding the mechanism involved in order to explore the mimicking effect of artificial membranes for various ion transport-based applications such as film-based catalysts for gas production (hydrogen and oxygen evolution reactions) [4,5], energy storages (capacitors and batteries) [6-8], and membranes for ionic and molecular separation [9-11]. Instead of artificial membranes in living cells, ions transport can also relate to cell stabilities, helping us to understand the fundamental mechanisms of ion transport in vitro and in vivo [12].

Two-dimensional (2D) materials are emerging categories of nanostructure materials which include graphene [13,14], transition metal dichalcogenides (TMDs) [11], hexagonal boron nitrile (h-BN) [15], and MXene [16]. The structure of these 2D materials can be controlled in many forms, including being stabilized in single or multiple layers or forming heterostructures, offering unique properties (electrical, thermal, optical and electrochemical, to name just a few) when compared to higher dimensional materials in bulk form [17]. For example, graphene displays higher levels of conductivity (including electrical and thermal conductivity) and a higher surface area than graphite [18]. Meanwhile, TMDs provide better optical properties than graphene materials due to their tuneable band gaps, which can be modified by reducing material thickness and used for optical applications in the visible spectrum. In addition, h-BN is categorized as an insulator that has a smooth surface and only a minimal lattice mismatch with graphite $[19,20]$. This leads to ultrahigh carrier mobility in graphene when it is integrated with h-BN [21-23].

The review describes the fundamental properties of capacitance and ion transport in various 2D materials, and offers novel applications based on various potential technologies from the macro to the nanoscopic perspective. The review describes a well-known capacitance models, including the Helmholtz, Gouy-Chapmann and Stern-Otto models, as well as the capacitive model in two dimensional materials, which explain their ion transport properties. We also show that, in addition to energy storages (i.e., supercapacitors and osmotic energy), the ion-transport devices (i.e., the stimulus-responsive microsupercapacitors) can generate new functionalities through their response to the external stimulus. Such functionalities include direct visualization of energy storages, light-induced energy storage and photodetections, and ion transport controls, as shown in Figure 1. These prominent, man-made technologies imitate the ion transport in living cells. To understand the extended capabilities of ion transport in artificial devices, it is important to connect with natural phenomena in living bacterial cells. This review aims to provide a better understanding of fundamental knowledge of ion transport technologies in order to examine further potential applications. 


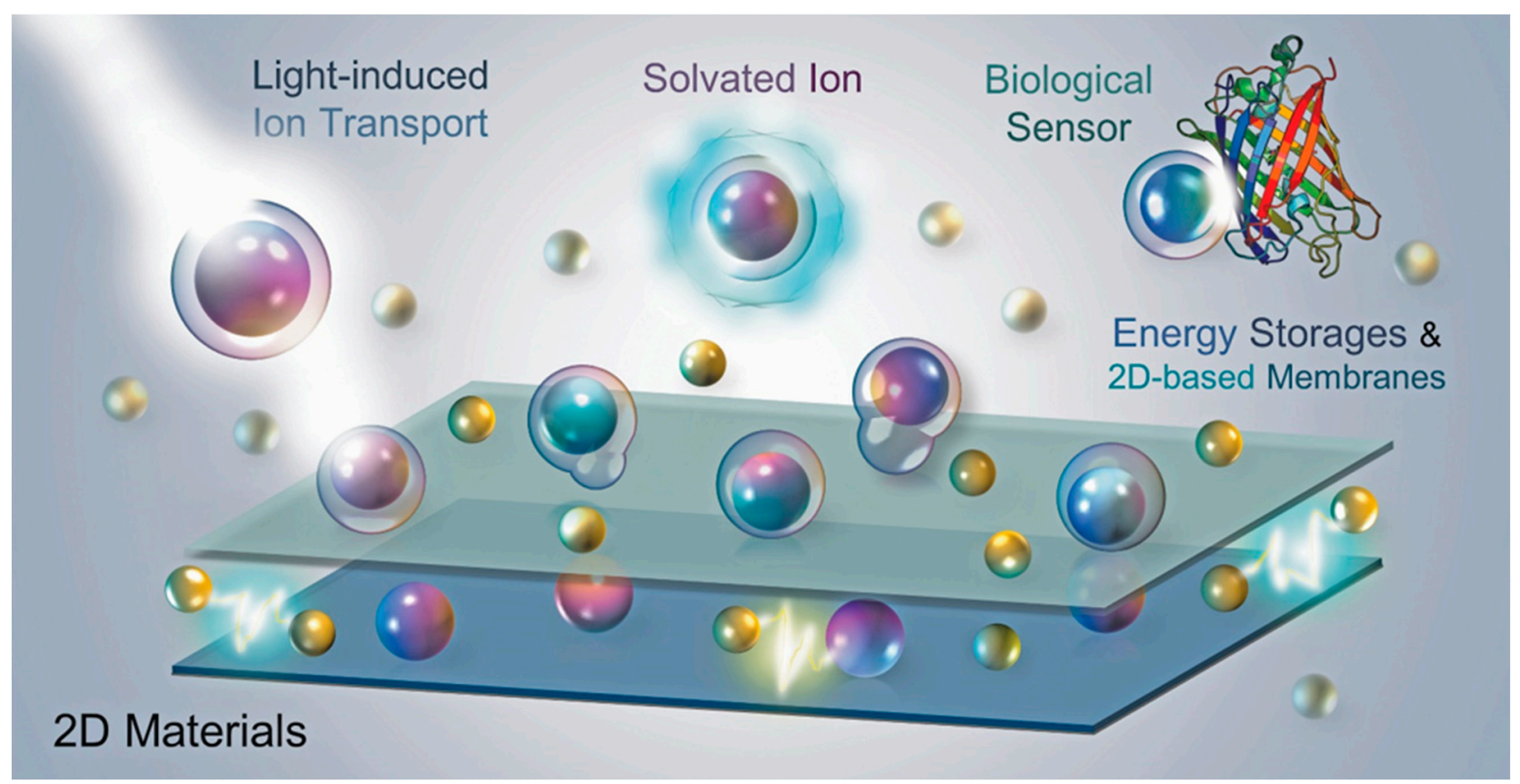

Figure 1. Diagram showing the potential applications of ion transport through two-dimensional (2D) materials, including the energy storages, 2D-based membranes for water purifications and energy harvesting (blue energy), light-induced ion transport, and biological sensors.

\section{The Principle of Capacitive Ions}

In general, capacitance represents the amount of electrical charge accumulated on the surface of the electrode over the applied electrical potential. Any system that can be electrically charged will exhibit a capacitive behavior [24]. In this context, the background knowledge of capacitive behaviors are described, leading to the understanding of ionic adsorption and transportation. Examples include the capacitive behavior of metallic electrodes and of two-dimensional (2D) materials such as graphite, graphene and transition metal dichalcogenides (TMDs) family. These concepts should assist the development of the electrochemical devices (also refer to the electrochemical system) i.e., energy storages $[6,25,26]$, capacitive deionization [27], 2D-based membrane (electrochemical ions sieving) $[9,28-30]$, and ion transport controls [31-33].

\section{Metallic Electrode Capacitance}

To understand capacitive behavior in general, it is crucial to know the principle of capacitive behavior models on metallic electrodes, which provides a basic understanding of the capacitance of more advanced materials. Typically, the capacitance of a metallic surface can be described using electrical double layer (EDL) models, which explain the accumulation of charge on electrodes and electrolyte interfaces. The Helmholtz model is a well-recognized model that can be used to explain charge storage properties [34]. The as-mentioned model refers to the adsorption of monolayer ions at the electrode and electrolyte interface under polarized conditions. Ideally, opposite charges migrate to the electrode's surface to maintain neutrality on a so-called Helmholtz plane (which also refers to ionic transport described below) [35]. As Figure 2 shows, the capacitance of the electrode is clearly based on the amount of the stored opposite charge on the plane, and under these circumstances, the capacitance of the electrode should depend directly on the specific surface area of the electrode interface and the charge separation distance. The Helmholtz capacitance $\left(C_{H}\right)$ is shown in Equation (1) [34]:

$$
C_{H}=\frac{\varepsilon_{0} \varepsilon_{r} S}{d}
$$


where $\varepsilon_{0}$ is the dielectric constant in a vacuum $\left(\sim 8.854 \times 10^{-12} \mathrm{~F} \mathrm{~m}^{-1}\right), S$ is the area of the electrode ( $\mathrm{m}^{2}$ per unit), and $d$ is the charge separation distance $(\mathrm{m})$, which can be measured from the center of the absorbed ions to the electrode plane. This number can be approximated by the Debye length, while $\varepsilon_{r}$ is the relative dielectric constant of the solvent. This number depends on the solvent properties-e.g., the $\varepsilon_{r}$ for water at room temperature is approximately 78.6 , but changing the electrolyte concentration or the dimensions of the materials can affect to the value of $\varepsilon_{r}[35,36]$. Garlyyev et al. also showed that the $C_{H}$ depends on the hydrated ionic size where the neat ions typically form a hydration shell among their ions due to its thermodynamic stability. Once the hydration shell becomes smaller, the $C_{H}$ tends to be larger due to the depletion of charge separation distance [37].

(a)

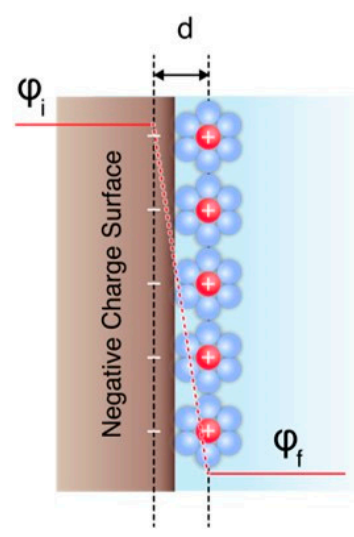

(b)

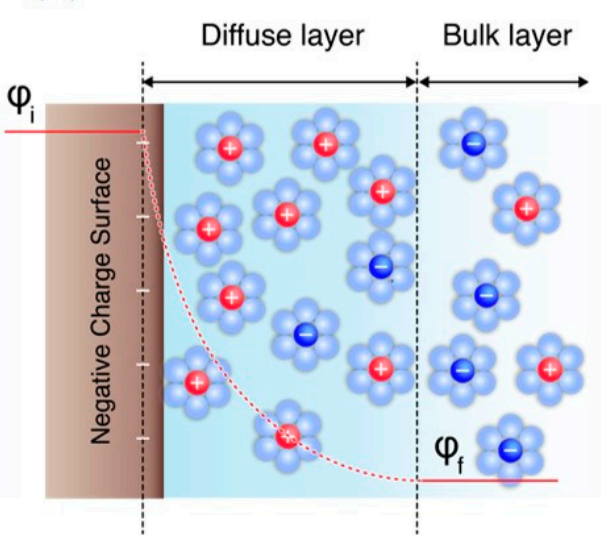

(c)

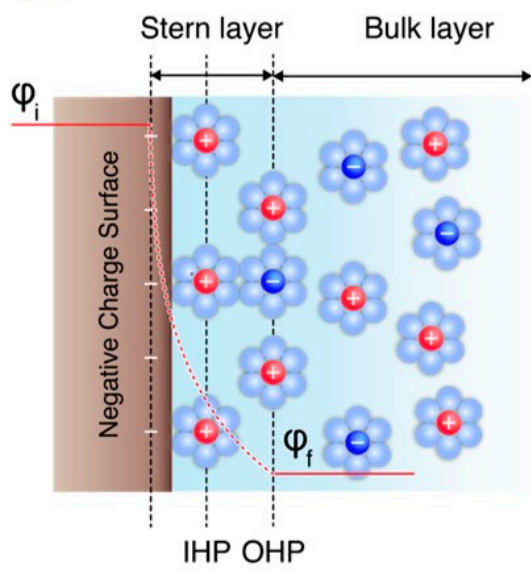

Figure 2. The principle of capacitance model based on the metallic electrode (a) Helmholtz model, (b) the Gouy-Chapman model or so-called diffuse layer capacitance, and (c) the Stern-Otto model.

However, it is clear that the Helmholtz model shown in Figure 2a neglects many parameters that may contribute to actual capacitance, such as electrical potential, dipolar movement interaction and the concentration profiles of ions in the electrolyte [24]. A more refined model, which included these parameters, was proposed by Gouy and Chapman (Figure 2b), the mathematical properties of which are shown in Equation (2) [24]:

$$
C_{\text {diff }}=\sqrt{\frac{2 \varepsilon(z e)^{2} I_{0}}{k T}} \cosh \left(\frac{z e \varphi}{k T}\right)
$$

where $z$ is the valence of charged ions, $I_{0}$ is the ionic density, $k$ is the Boltzmann constant $\left(1.381 \times 10^{-23} \mathrm{~J} \mathrm{~K}^{-1}\right), T$ is the absolute temperature, and $e$ is the elementary charge $\left(1.602 \times 10^{-19} \mathrm{C}\right)$ [24]. This model is valid for a diluted electrolyte condition of below $0.1 \mathrm{M}$. Again, this is not suitable for the highly charged double layers; thus, a more precise model that include the Helmholtz layer and the diffuse layer was proposed by Stern and Otto, as shown in Figure 2c. The capacitance of the metallic electrode, or the measured total interface capacitance $\left(C_{\text {total }}\right)$ is described in Equation (3) [38]:

$$
\frac{1}{C_{\text {total }}}=\frac{1}{C_{H}}+\frac{1}{C_{\text {diff }}}
$$

\section{The Capacitance of Two-Dimensional Materials}

The capacitive behavior of 2D materials can be classified into various categories based on different criteria. One such method of classification is to distinguish the capacitive properties according to the electrical properties of the $2 \mathrm{D}$ materials used, namely semimetallic, semi-conductor and insulator. It is recognized that graphene (also referred to 
highly ordered pyrolytic graphite) is a suitable material for explaining capacitance of semi-metallic materials [39]. This allows us to further describe the capacitance dependence of those materials including carbonaceous, and layered materials from a nanoscopic to a macroscopic perspective. This section discusses the intercalation capacitance of layer materials, including TMDs and h-BN, which represent the capacitive behavior of semiconductor and insulator materials.

\subsection{The Principle of Graphene and Carbonaceous Materials' Capacitance}

In general, the capacitance of carbonaceous materials based on the electrical double layer (EDL) relates to the Stern's model discussed above, with further modifications due to the limit of charge carrier density on carbon-based materials. We can therefore add an extra term (a "space charge capacitance") to Stern's model, as shown in Equation (4) [24]:

$$
\frac{1}{C_{\text {total }}}=\frac{1}{C_{S C}}+\frac{1}{C_{H}}+\frac{1}{C_{\text {diff }}}
$$

This model can be applied to semi-metallic electrodes such as graphite (also referred to as graphene-based materials) because the low charge carrier density of the material means that the internal space-charge capacitance becomes significant [24]. The theory of minimum space charge capacitance $\left(C_{s c(0)}\right)$ can be calculated using the semiconductor model if we assume that the potential drop in capacitance inside the solid behaves like a semiconductor, as shown in Equation (5). Considering the effect of potential dependence, the space charge capacitance can be also calculated using Equation (6), where $\varepsilon_{r}$ refers to the solid phase (e.g., in the graphite a-b plane $\varepsilon_{r}=2.61$, along the crystallographic c-axis $\left.\varepsilon_{r}=3.28\right), c$ is the electronic charge carrier density $\left(\sim 4 \times 10^{18}\right.$ carriers $\left.\mathrm{cm}^{-3}\right)$, and $\varphi_{i}$ is the potential at the surface of the electrode [38]:

$$
\begin{gathered}
C_{S C(0)}=\sqrt{\frac{2 \varepsilon_{0} \varepsilon_{r} e^{2} c}{k T}} \\
C_{S C}=C_{S C(0)} \cosh \left(\frac{\varphi_{i} e}{2 k T}\right)
\end{gathered}
$$

Unfortunately, this space charge model cannot cover all 2D material contexts, especially low dimensional or nanomaterials like graphene. This is because there is a limited density of state (DOS) at or near the Fermi level, while the electrons of graphene samples occupy higher energy states. In such cases, the capacitive behaviour of low dimensional materials are described by the quantum effect [40], which arises when low dimensional graphene samples (below 4-5 layers) are applied [24]. The total capacitance of low dimensional graphene can be defined using Equation (7), while the quantum capacitance can be defined according to Equation (8) [40]:

$$
\begin{aligned}
\frac{1}{C_{\text {total }}} & =\frac{1}{C_{q}}+\frac{1}{C_{H}}+\frac{1}{C_{\text {diff }}} \\
C_{q} & =\partial Q / \partial \varphi=e d N
\end{aligned}
$$

Electronic charges can be obtained from the integration of the density of states (DOS, $D(E)$ ), and the Fermi-Dirac distribution $[f(E)]$ when changing the applied potential, as shown in Equation (9). The general solution of quantum capacitance can be seen in Equation (10), in which $q$ is the electron charge, $\hbar$ is Planck's constant divided by $2 \pi, v_{F}$ is the Fermi velocity of the Dirac electron (approximately $v_{F} \approx c / 300$ ), $E_{F}$ is the Fermi energy (as calculated from $E_{F}=e \varphi_{c h}$ ), and $\varphi_{c h}$ is the local potential of graphene [24,40]:

$$
Q=e \int_{-\infty}^{+\infty} D(E)[f(E)-f(E-\varphi) d E]
$$




$$
C_{q}=\frac{d Q}{d \varphi}=\frac{e^{2}}{4 k T} \int D(E) \sec h^{2}\left(\frac{E-\varphi}{2 k T}\right) d E
$$

\subsection{Capacitance of Graphene}

Graphene, a monolayer of carbon atoms arranged in a hexagonal formation, is an appropriate material for modelling the capacitance properties of carbon materials. This is because the carbonaceous materials (in any form) comprise numerous benzene ring units [41], and in this way graphene capacitance creates a connection with the carbon-based material. Generally, graphene stores the electrical charge via a process of physisorption (also known as electrical double layer capacitance, EDLC), thus the total graphene capacitance can be described using Equation (7). It is clear from this state that several parameters contribute to the measured graphene capacitance, including the active surface area of the materials, the electrolyte concentration, the potential applied, and the dimensions of the materials. The capacitance and ionic transport properties of exfoliated graphene was revealed by Iamprasertkun's group, who demonstrated that the capacitance of multilayered graphene is directly related to flake size, which reflects the overall surface area. It was found that capacitance decreases as flake size increases. The small flakes exhibit higher capacitance than larger flakes because smaller graphene flakes provide a higher concentration of edge planes [18]. This conforms with previous observations by Yuan et al., which reported that the capacitance of the edge plane $\left(\sim 1 \times 10^{5} \mu \mathrm{F} \mathrm{cm}^{-2}\right)$ is about four times higher than that of the basal plane $\left(\sim 4 \mu \mathrm{F} \mathrm{cm}^{-2}\right)$ [42]. It is also worth noting that the measured capacitance not only depended on the surface area of the electrode but also the ionic size of the electrolyte. This was clearly demonstrated by Garlyyev et al., who reported the influence of cationic identities to the Helmholtz capacitance in aqueous systems [37], proving that smaller hydrated ions provide less hydration size (here $\mathrm{Cs}^{+}$is considered) and the highest capacitance $\left(\mathrm{Li}^{+}<\mathrm{Na}^{+}<\mathrm{K}^{+}<\mathrm{Rb}^{+}<\mathrm{Cs}^{+}\right)$. Note that this work measured the capacitance of the cation using gold, and platinum electrodes (model system) in the three-electrode configuration (the anion was fixed as $\mathrm{ClO}^{4-}$ ). They plotted the relationship of capacitance with respect to the potential applied (a so-called "capacitance-potential (C-E) curve") using the impedance technique. It is also found that the following trend concurs with our observation of the basal plane graphite, where basal plane capacitance can vary from 4.7-9.4 $\mu \mathrm{F} \mathrm{cm}{ }^{-2}\left(\mathrm{Li}^{+}<\mathrm{Na}^{+}<\mathrm{K}^{+}<\mathrm{Rb}^{+}<\mathrm{Cs}^{+}\right)$depending on the size of the hydrated cations [43]. Obviously, these numbers are much lower than the proposed theoretical value $\left(\sim 21 \mu \mathrm{F} \mathrm{cm}^{-2}\right)$ [40], due to the influence of space charge capacitance (also referred to as quantum capacitance in the low dimension materials). In fact, the quoted theoretical value of graphene was measured using the polycrystalline electrode in the ionic liquid electrolyte $\left(\mathrm{BMIM}-\mathrm{PF}_{6}\right)$ to obtain the Helmholtz capacitance (ignoring the quantum capacitance of graphene, and assuming that similar interfacial properties exist between graphene and platinum) [40]. This is why it is impossible to obtain a reading of $550 \mathrm{~F} \mathrm{~g}^{-1}$ even in the case of a perfect monolayer graphene [44].

As well as surface area, the effect of electrolyte concentration is also crucial when measuring total capacitance. Changing the electrolyte concentration can greatly increase the $C_{\text {diff }}$ at the PZC (Figure 3), which explains why total capacitance increases when higher electrolyte concentrations are applied. However, if the electrolyte concentration exceeds $0.1 \mathrm{M}$, the $C_{\text {diff }}$ becomes negligible due to the reduction of the diffusion boundary (the decrease in Debye length) [24,39]. Although $C_{\text {diff }}$ makes no contribution to the high electrolyte concentration (ionic liquid, or "water-in-salt"), the total capacitance can be increased because the space charge and quantum capacitance depend on the applied potential. Iamprasertkun et al. demonstrated that the capacitance of the basal pyrolytic graphite plane can be increased by up to $10 \mu \mathrm{F} \mathrm{cm}{ }^{-2}$ to reflect the "water-in-salt" condition (high KF concentrations of up to $17 \mathrm{M}$ ). However, the diffusivity of the redox molecule shrinks in high concentrations, leading to inefficient ionic transport. It can therefore be clearly seen that a significant relationship exists between capacitance and ionic transport. 


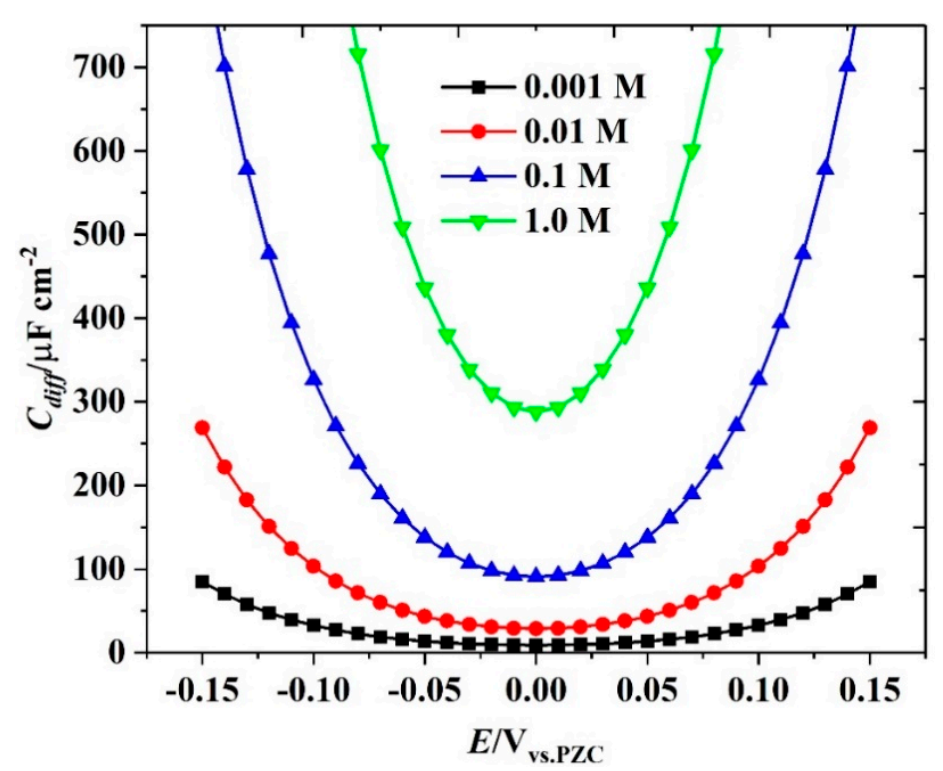

Figure 3. A plot showing the effect of electrolyte concentration on diffuse layer capacitance $\left(C_{\text {diff }}\right)$ with respect to the applied potential vs. potential zero charge (PZC), calculated from Equation (2) for mono valence ions.

\subsection{Capacitance of Layered Materials}

The intercalation of external species into the spacing between layered materials was first demonstrated using graphite in 1841. By immersing graphite in either a mixture of sulfuric and nitric acids or alkaline metal solutions, the material swelled, resulting in the cleavage of individual planes [45,46]. Among the layered materials, other conductive materials such as TMDs (e.g., $\mathrm{MoS}_{2}$ and $\mathrm{WS}_{2}$ ) can be intercalated by n-butyllithium ( $n$-BuLi) under mild conditions. This causes an expansion in the interlayer spacing of $\sim 0.5 \AA$ due to the mechanism of electron transfer from lithium to materials and diffusion into a layered structure.

Joensen et al. [47] first synthesized single-layer $\mathrm{MoS}_{2}$ using lithium intercalation by soaking bulk $\mathrm{MoS}_{2}$ in a solution of $n$-BuLi in hexane for a period of time, resulting in the intercalation of lithium between the $\mathrm{MoS}_{2}$ layers. The intercalated $\mathrm{MoS}_{2}$ was then immersed in water, which produced a vigorous hydrogen evolution between the layers, causing an expansion of the $\mathrm{MoS}_{2}$ layers and a reduction between the interlayer forces. The material was agitated to produce the lower number of layers, eventually resulting in mono-layer $\mathrm{MoS}_{2}$ nanosheets stabilized in suitable solvents (Figure 4) [48]. However, this technique takes a long period of time due to the diffusion of alkali metals into the interlayer space, especially the limitation to control the amount of $\mathrm{Li}$ insertion.

In terms of two-dimension materials, graphene not only plays a crucial role in a variety of applications but also creates transition metal oxides or chalcogenides. The difference between graphene and transition metal-based layer materials lies in the charge storage mechanism. The layer materials store the electrical charge by changing the oxidation state of the metal atoms, while graphene stores the charge via EDLC (Figure 5). The capacitive properties of layer materials can be classified into three main types: Surface capacitive charge store on the (non-insertion capacitance), pseudocapacitive charges, which represents an intermediate process between capacitive and battery, and Faradaic-battery like behavior [49]. The capacitive behavior describes the ionic charge stored on the surface of the electrode either by physisorption or surface redox processes as shown in Figure 5 (Type A). 


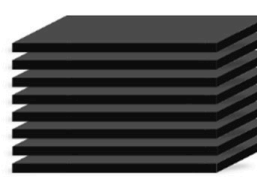

3D crystals (graphite)
External species

$\overrightarrow{\text { (e.g. n-BuLi) }}$

$\oplus \mathrm{Li}$ ions

- $\mathrm{Li}^{+}$intercalation

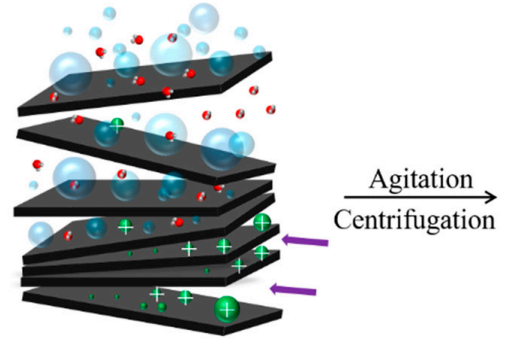

$\mathrm{Li}^{+}$intercalation

following with $\mathrm{H}_{2}$ gas

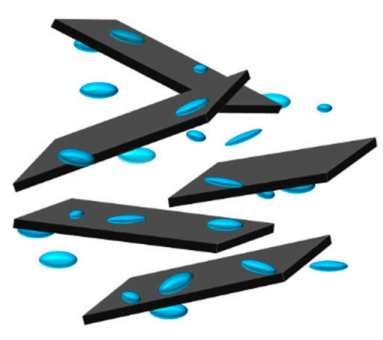

2D crystallites (large sheets) stabilized by solvent

Figure 4. Schematic of ion intercalation: $\mathrm{Li}$ ions are intercalated within the interlayer spacing via chemical or electrochemical reactions. The crystals swell, leading to weak van der Waals interactions, agitation (i.e., ultrasonication, shear forces or thermal process) then results in the exfoliation of individual layers.

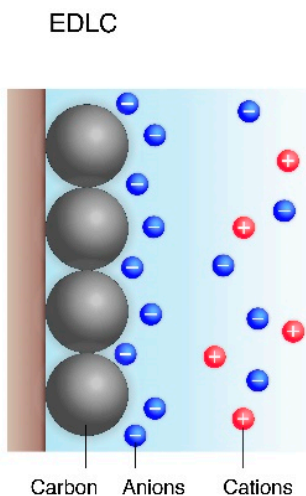

\section{Redox pseudocapacitance}

$\odot \mathrm{O}+\mathrm{ze}^{-} \cdot \mathrm{R}$

$\ominus$

๑

(

$\oplus$

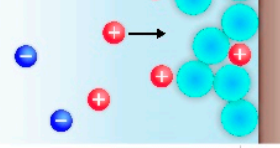

Redox-active material
Intercalation

pseudocapacitance

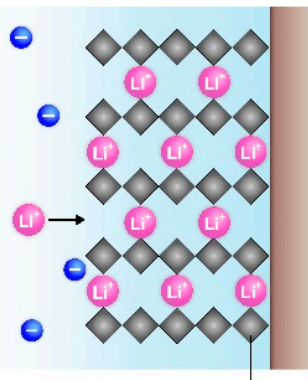

Redox host material

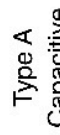

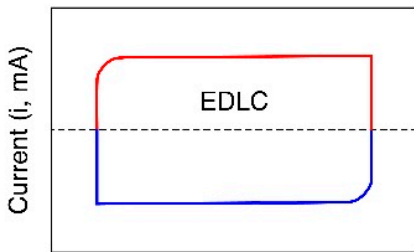

Potential (V)

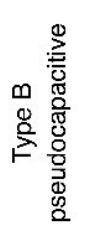

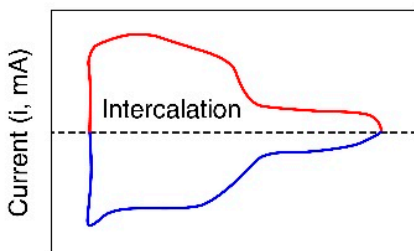

Potential (V)

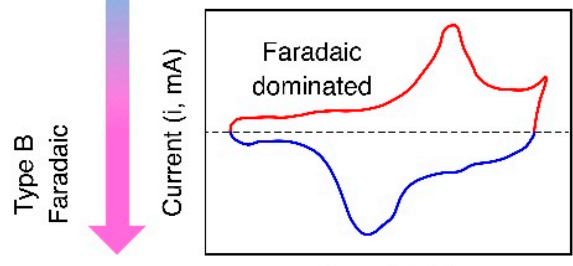

Potential (V)

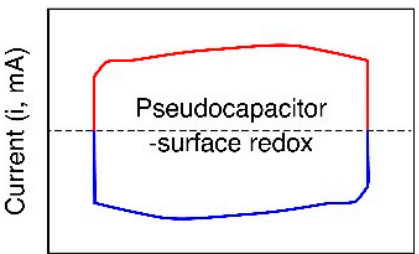

Potential (V)

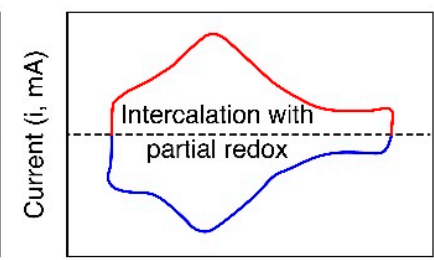

Potential (V)

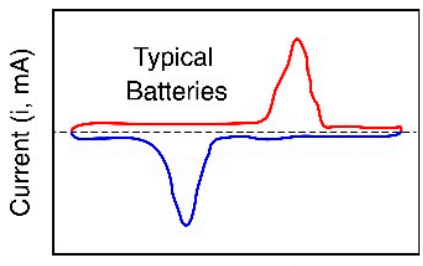

Potential (V)

Figure 5. Schematic showing the charge storage mechanism of layer materials and providing the electrochemical response via CV technique in each of the charge storage properties. These are classified as (1) capacitive, (2) pseudocapacitive, and (3) Faradaic processes. 
This pseudocapacitive surface process can be defined according to the center of metal atom that contribute to the Faradaic process, which are located near the surface atom of the metal oxide/chalcogenides at a distance of $L \ll(2 D t)^{0.5}$, where $D$ is the diffusion coefficient for charge-compensating ions $\left(\mathrm{cm}^{2} / \mathrm{s}\right)$, and $t$ is time $(\mathrm{s})$. This means that the Faradaic reaction is electrochemically indistinguishable from the non-Faradaic reaction [49]. The EDLC and surface redox can be distinguish by the current displayed when the surface redox process shows a higher current response. To describe the pseudocapacitive (Type B) and faradaic (Type C) processes further, we can classify into two major mechanisms: ion intercalation and Faradaic reaction, respectively. The Faradaic electron transfer to center of metal atoms are typically enabled by the intercalation of charge-compensating ions such as $\mathrm{Li}^{+}$or $\mathrm{Na}^{+}$[17]. This intercalation process can occur with partial redox, which can be distinguished by the electrochemical response using the CV technique (Figure 5). In addition to the intercalation process, it is noticeable that the battery type can also be completely dominated by the faradaic process, where the CV clearly exhibits oxidation and reduction peaks. The intercalation can also be carried out electrochemically by applying an electric potential to force ions into the interlayers. The Li-ion intercalation into the layered bulk structures was performed with the active material (TMDs; $\mathrm{MoS}_{2}$ and $\mathrm{NbSe}_{2}$ ) as a cathode inside an electrochemical cell using the Li metal and $\mathrm{LiPF}_{6}$ as the anode and electrolyte, respectively $[50,51]$. This has been demonstrated to reduce the reaction time from a couple of days to a few hours, while also enabling the reaction to be monitored (staging) throughout the intercalation process.

\section{Principle of Ion Transport}

\subsection{Ion Selectivity}

The cations and anions can be separated out due to the charged channel surface. This is because the opposite charged ions (the counter-ions) would preferentially transport through the surface-charged channel faster than the same charged ions (co-ions). This is so-called ion selectivity which is based on the electrical double layer (EDL) structure of the charge distribution at the interface between a charged electrode surface and the surrounding electrolyte solution. The phenomena occurs via electrostatic interaction at which the charged channel surface attracts the counter-ions and repels the co-ions (Figure 6a) [1,52], This results in a decrease in co-ions concentration and an increase in counter-ion concentration. This causes the local potential to decrease as a function of the charged electrode surface-electrolyte distance, as shown in Figure 6b. The two layers are the stern layer and the diffusion layer. The stern layer, known as the compact (rigid) layer, possesses two planes. The first plane, which is located at the surface, contains solvent molecules and charged ions adsorbed tightly onto the charged surface. The adsorbed ions are defined as specifically adsorbed ions (counter-ions) at which point they are not solvated. Moving further away into the second plane, solvated ions are then encountered due to their increase in solvated ions size which is unable to reach near the surface. The interaction between the solvated ions and the charged surface is governed by coulombic forces as the solvated ions are non-specifically adsorbed [52-54]. The diffuse layer lies beyond the stern layer, in which the solvated ions start to be more scattered and increasingly less ordered when stepping away from the charged surface. The ion distribution of this layer is influenced by coulombic interactions between charged ions and charged electrode surface, and thermal motions. This indicates that the potential-distance profile has two regions that are linear (stern layer) and non-linear (diffuse layer), where the potential decay as a function of distance from the charged electrode surface (Figure 6b). The density of solvated ions in the diffuse layer is much tighter at high electrode potential and less tight when they are away from the charged surface [52-54]. This causes the exponential decrease in potential as a function of diffuse layer distance. Moreover, the thickness of the EDL also relates to the Debye screening length $(\lambda)$, which depends on the ionic strength $(I)$ of the electrolyte, corresponding to $\lambda \propto I^{-1 / 2}$ [55]. For the nanocapillary channel, the thickness of the EDL plays a crucial role in ion transport, at which the EDL of the opposite 
charged surfaces are overlapped together. This can be attributed to the formation of almost a unipolar ions in the channel (abundant counter-ions), which can be observed in ion selectivity during transport through the channel, as shown in Figure 6c.

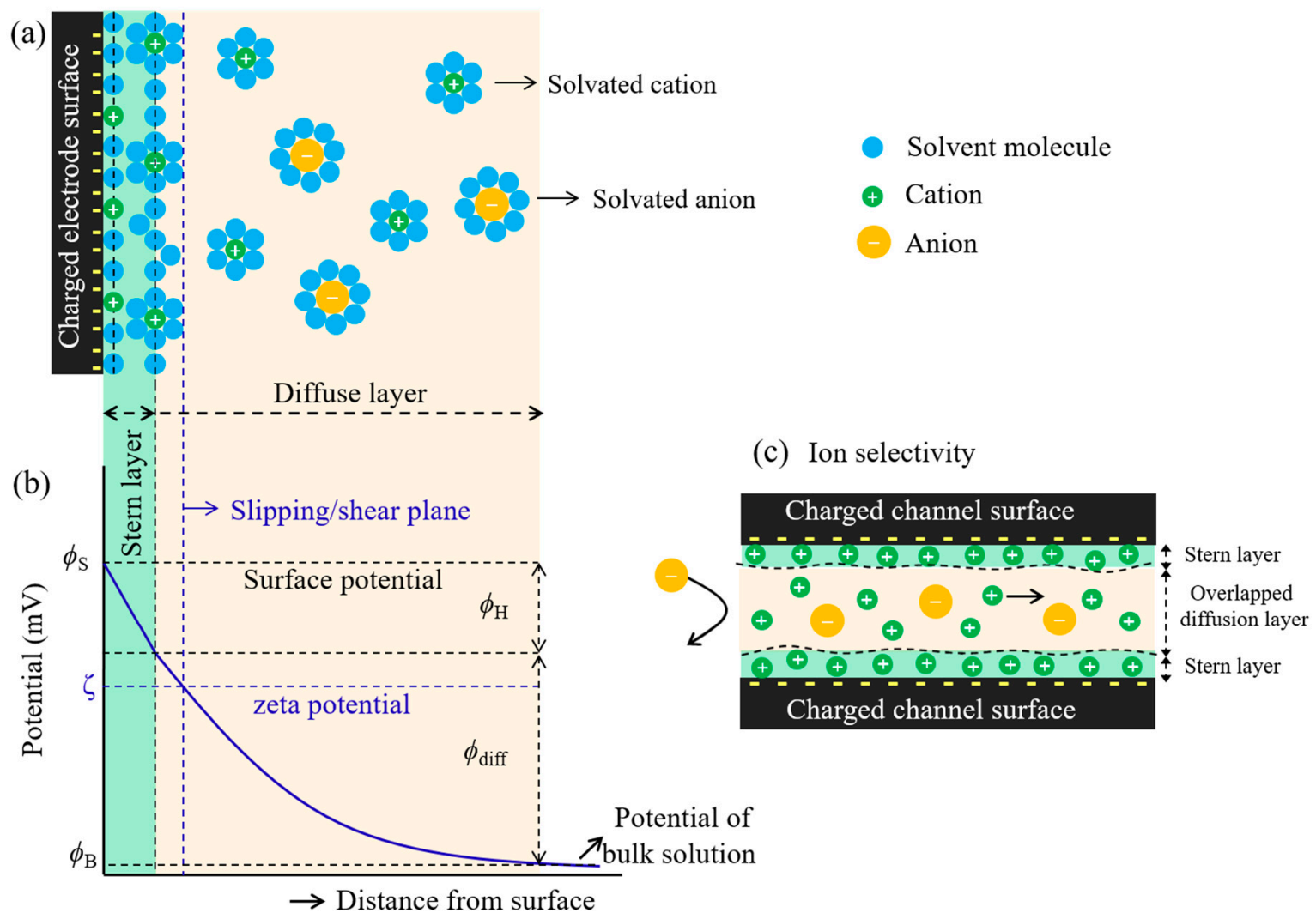

Figure 6. Schematic illustration of the electrical double layer (EDL). (a) The model of the EDL of the charged electrode surface immersed in the electrolyte solution at which negative potential bias is applied. (b) The potential profile of the electrode surface to the solution, which consists of the two steps of the decreasing potential as a function of the electrode distance. $\varphi_{\mathrm{S}}, \zeta$, and $\varphi_{\mathrm{B}}$ represent the potential at the electrode surface, slipping/shear plane (zeta potential), and the bulk electrolyte solution, respectively. $\varphi_{\mathrm{H}}$ and $\varphi_{\text {diff }}$ are the potential of the Helmholtz plane and diffuse layer, respectively. (c) Ion selectivity inside the charged channel shows the two EDLs between the charged surfaces (overlapping diffuse layers), which allows counter-ions to pass through the channel but excludes co-ions.

To determine the magnitude of ion selectivity, the electrical measurement was used to measure the zero-current potential (so-called the reversal potential, $E_{\text {rev }}$ : the potential at which the sign of current reverses) or the electromotive force (i.e., the current at which the potential is zero) for the charged channels. If the concentration of cations and anions between both sides of charged channel (the feed and permeate sides) are known, the ion selectivity can be determined in terms of the permeability ratio between cations and anions $\left(P^{+} / P^{-}\right)$. This can be deduced from the $E_{\text {rev }}$ as Equation (11):

$$
\frac{P^{+}}{P^{-}}=-\frac{\mathrm{z}_{-}^{2}}{\mathrm{z}_{+}^{2}}\left(\frac{\left[C^{-}\right]_{f}-\left[C^{-}\right]_{p} \exp \left(\mathrm{z}_{-} \frac{F E_{m}}{R T}\right)}{\left[C^{+}\right]_{f}-\left[C^{+}\right]_{p} \exp \left(\mathrm{z}_{+} \frac{F E_{m}}{R T}\right)}\right)\left(\frac{1-\exp \left(\mathrm{z}_{+} \frac{F E_{m}}{R T}\right.}{1-\exp \left(\mathrm{z}_{-} \frac{F E_{m}}{R T}\right.}\right)
$$

where $\left[\mathrm{C}^{+}\right]_{f}$ and $\left[\mathrm{C}^{-}\right]_{p}$ are the concentration of cations and anions in the feed and permeate sides, respectively, and $z_{+}$and $z_{-}$are the valences of the cations and anions, respectively. To obtain the zero-current potential, the drift-diffusion experiment was performed, driven by the concentration gradient and the applied electrical field [1,56]. In addition, the ion permeability is related to ion mobility $(\mu)$ according to solubility-diffusion theory and the 
Nernst-Einstein relationship as $P=\frac{R T \mu}{F} \frac{\beta}{l}$, where $\beta$ and $l$ are the partition coefficient and the membrane thickness, respectively $[1,57]$. This suggests that the permeability ratio between cations and anions $\left(P^{+} / P^{-}\right)$can be referred to mobility ratio $\left(\mu^{+} / \mu^{-}\right)$when the membrane and its thickness used are equivalent.

\subsection{From Nanometer-Sized to Angstrom-Sized Channels}

The process of ion transport in nanochannels has received a great deal of attention This plays a crucial role in the development of nanofluidics, ion sieving $[9,11,58]$, and other nanoscale technologies such as energy storage [4,43], active ion gated control [59], and ion rectifications [60]. This has inspired various research directions into the fabrication of synthetic nanochannels from inorganic materials with well-defined properties (various types of geometries) and studying the mechanisms of ion transport [61]. As a development in nanochannel fabrication, this can allow researchers to study electrokinetic models of the transport of electrolyte ions through nanometer-sized slits [62-64]. Nanochannels can initially be fabricated from silica (lab-on-a-chip) with a height of $100 \mathrm{~nm}$ (Figure 7a) [64], and it was found that a steady conductance at low salt concentrations inside the nanochannels results from the dominance of surface charge density in the nanochannels. This leads to the effectiveness of the surface charge density in the nanochannels, leading to the abundance of counter-ions which results in electroneutrality inside the channels [63,64]. Schoch et al. [63] increased the surface-area-to-volume-ratio by reducing the height of channel to $50 \mathrm{~nm}$ (Figure $7 \mathrm{~b}$ ), showing that the surface charge plays a crucial role as a greater fraction of the total charge is attached to the channel's wall. This is attributed to the regulation of ionic flow inside the charged nanochannels.

To control ionic current during the transport of ions through a channel, the height of the channel should be less than the Debye screen length (1-100 nm in height) and the channel's wall should be charged [65]. A unipolar solution of counter-ions can be created inside the nanochannel at the electrolyte concentration neutralizing the surface charge, while the co-ions are electrostatically repelled from the channel's wall. This creates the ionic current inside the channel which depends on the surface charge density in the concentration - although the ionic current becomes less involved in surface charge density where the bulk concentration increases $[60,65]$. The height of the channel should be similar to the nanoscale channels inside transmembrane proteins, which control the transport of ions and molecules. As the magnitude of the EDL is evaluated from the Debye screening length, which relates to the ionic concentration, this causes the overlapping EDL inside the channel depending on the relation between size of channels and the ion concentration. Due to traditional synthetic channels with heights in the range of 1-100 nm, the EDL overlap can occur at very low concentrations $(<10 \mathrm{mM})$, which is far lower than the concentrations observed in physiological solutions [59]. Duan et al. [59] demonstrated ion transport by reducing the size of nanochannel to $2 \mathrm{~nm}$ in height, providing the connecting EDLs from each side of channel's wall at $100 \mathrm{mM}$ concentration, which is close to physiological concentrations. The fluid nanochannels thus obtained can be used to mimic protein channels in order to study the ion/molecular transport in liquid nanoconfinement [59-61].

Although an $\mathrm{SiO}_{2} / \mathrm{Si}$-based nanochannel with a $2 \mathrm{~nm}$ height with hydrophilic surfaces showed almost four-fold increase in ion transport when compared to a $25 \mathrm{~nm}$ height channel in terms of bulk ion transport, but the mechanism behind the process is not fully understood [59]. The process may result from the overlapping of the hydrogen bonding network of the two hydration shells next to the hydrophilic surfaces [59]. To understand and prove this, the hydrophobic nanochannels should be fabricated under the same experiment conditions. Jung et al. [66] first fabricated rectangular-shaped nanochannels using graphene nanosheets across the surface to provide the hydrophobic noanoconfinement $[66,67]$. They found that the $3.6 \mathrm{~nm}$ graphene-based nanochannels performed an excellent level of ion transport, providing great ionic conductance by over two orders of magnitude compared to the nanochannels in the absence of graphene coating in an aqueous solution. This can be explained by the fact that the surface of the graphene nanochannels is much cleaner 
and smoother than that the $\mathrm{SiO}_{2} / \mathrm{Si}$ nanochannels (10-50 nm height channels showing significantly low ion transport).

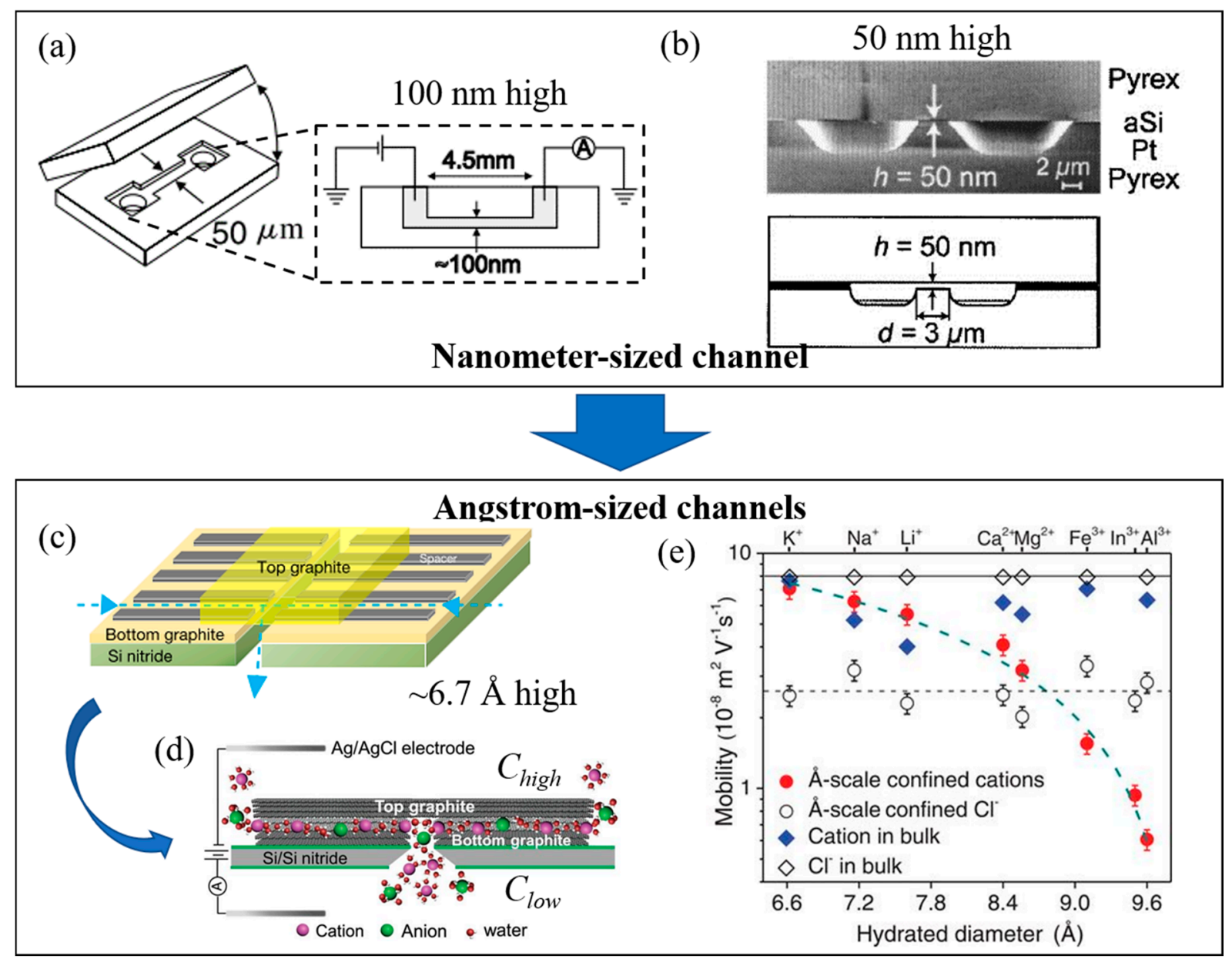

Figure 7. Schematic illustration of the fabrication of slits in nanometer-sized channel (top image) and angstrom-sized channels (bottom image). (a) Nanochannel assembly with cross-sectional side view (100 nm high). (b) Cross section of nanochannels (50 nm high) as defined by the thickness of the silicon layer and the nanochannel length $(d=3 \mu \mathrm{m})$. (c) Schematic of graphene capillary devices showing the composition of each device. The arrow indicates the flow direction of electrolyte. (d) Schematic of ion transport under nanocapillary channels (channel height $=\sim 6.6-6.7 \AA$ ) driven by the drift-diffusion techniques. (d) The individual ion mobility in $\AA$-confined channels (using bilayers of graphene as spacers between the materials) as a function hydrated diameter, which were compared to their ion mobilities in bulk solutions. Reprinted with permission from (a) ref. [64] Copyright (2004) American Physical Society (United States), (b) ref. [63] Copyright (2005) American Institute of Physics (United States), (c) ref. [68] Copyright (2016) Macmillan Publishers Ltd., and (d,e) ref. [69] Copyright (2017) The American Association for the Advancement of Science.

The effect of surface roughness on the Si-based nanochannels results in capillary channels that are imprecisely controlled. Radha et al. [68] first fabricated very narrow and smooth channels with atomic-scale precision (Figure 7c). This fabrication was based on van der Waals interaction, with atomically nanosheets at the top and bottom (i.e., graphite) separated by spacers made from laser-etched 2D crystals with a number of 2D layers using single and bilayers of $\mathrm{MoS}_{2}$ and graphene, respectively, as spacers. This allowed the rapid transport of water through the channels (around $1 \mathrm{~m} \mathrm{~s}^{-1}$ ) due to high internal capillary pressure (up to 1000 bar). Meanwhile, Esfandiar et al. [69] recently fabricated controlled nanochannels the dimensions of which approached the size of charged ions. This was used to study size effects in ion transport using drift-diffusion experiments as shown in Figure 7d. It was proved that the flat angstrom-scale channels exhibited small surface 
charges which enabled the investigation of solely steric effects such as ionic diameter and channel height. They discovered that ions with a hydrated diameter larger than the channel height $\left(D_{H}>6.7 \AA\right)$ can still transport, although the process leads to a reduction in ion mobility. This is due to the distortion of their hydration shells during ion transport process (Figure 7e). It was clearly seen that $\mathrm{K}^{+}$travels through nanochannels faster than $\mathrm{Cl}^{-}$, whereas $\mathrm{Al}^{3+}$ travels slower. Based on the different polarization of water molecules around cations and anions, hydrogen atoms and oxygen atoms attach preferentially to $\mathrm{K}^{+}$and $\mathrm{Cl}^{-}$, which consequently creates $\mathrm{OH}^{-}$groups that cover the exterior of $\mathrm{Cl}^{-}$. This results in extra friction between the $\mathrm{Cl}^{-}$and the channel walls, reducing mobility [69-71]. Therefore, the $\AA$-confined channel leads to notable asymmetries in speed between cations and anions of the same diameter.

\section{Ionic Sieving through 2D Material-Based Membranes}

A membrane can be defined as a thin physical interfacial material which possesses specific chemical and/or physical properties to control a selective species (i.e., charged ions/molecules, live cells, and various size of particles) passing through. In general, it can be classified by cross-sectional properties into isotropic membranes (homogeneous composition; microporous, nonporous dense, and electrically charged membranes) and anisotropic membrane (heterogeneous composition; Loeb-Sourirajan and thin-film composite membranes) [72,73]. As the various structures and function inside membranes, this can be used to control the transport of permeants which is based on pore size of membranes, diffusion (driven by concentration or pressure), and electrostatic repulsion. The different types of membranes are widely implemented for various filtration technologies such as particle separations (large molecules, gas, and ions), pervaporation, and reverse osmosis (RO) membranes. Electrically charged membranes can be classified as positively or negatively charge functional groups in the structural materials, which is so-called an anion-exchange membrane (AEM) and a cation-exchange membrane (CEM), respectively [72]. The mechanism of separation is mainly based on the electrostatic repulsion of the similar charge between the charge inside the membrane and charge of particles under the influence of an applied electric potential. The ion-exchange membranes (IEM) can be produced from various materials such as organic (e.g., liquid and polymer) [74,75], inorganic (e.g., carbon nanotube, graphene, transition metal dichalcogenides) $[9,11,76]$, and organic-inorganic hybrid (e.g., metal organic framework) materials [77-79].

2D material-based membranes can be generally classified into two main types: a porous 2D material monolayer and assembled 2D laminar membranes (i.e., stacked laminar multilayer 2D materials) as shown in Figure 8.

\subsection{Ion Transport through Porous 2D Materials Layers}

Typically, the nanoporous 2D membranes can be intrinsic [80] or fabricated using different methods such as electron/ion bombardments and oxygen plasma treatment [81-83]. O'Hern et al. demonstrated selective molecular and ion transport through nanoporous graphene (NPG) membranes based on intrinsic defects [80] and tunable sub-nanometer pores [81], respectively. By controlling the ion bombardment and oxidative etching time, they introduced the desired nanopores in single-layer graphene with $1 \mathrm{~nm}$ in diameters which proved highly selective for nanofiltration applications such as the removal of small organic contaminants and more efficient desalination technologies [81-83]. Surwade et al. [83] successfully constructed an NPG membrane with nanometer-sized pores (0.5-1 nm in diameter) by employing an oxygen plasma etching technique for water desalination (see Figure 8a). The as-prepared membrane can decrease ion mobility nearly $100 \%$ with a large amounts of water permeation around $250 \mathrm{~L} \mathrm{~m}^{-2} \mathrm{~h}^{-1}$ bar $^{-1}$ under osmotic pressure as a driving force. However, the resulting water flow rate was over an order of magnitude lower than the calculation value $\left(2750 \mathrm{~L} \mathrm{~m}^{-2} \mathrm{~h}^{-1} \mathrm{bar}^{-1}\right)$ [84] at a comparable pore size (ca. $20 \AA^{2}$ ). This is because the as-prepared nanopores were blocked 
from electrostatic interaction between hydrated ions and functional group-terminated nanopores.

(a) Porous 2D materials Monolayer

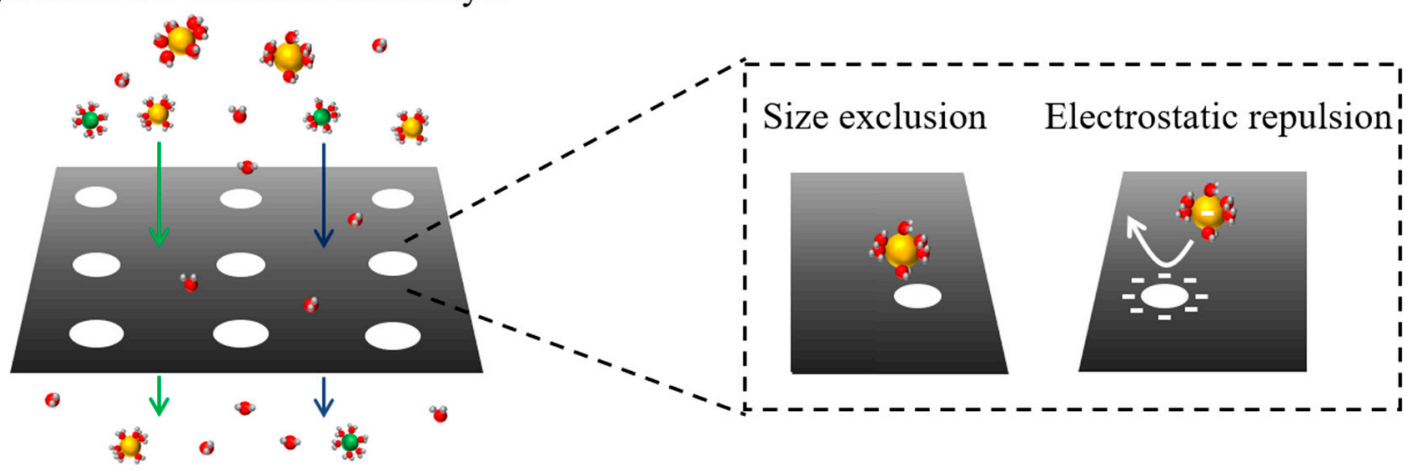

(b) Assembled 2D Materials Laminates

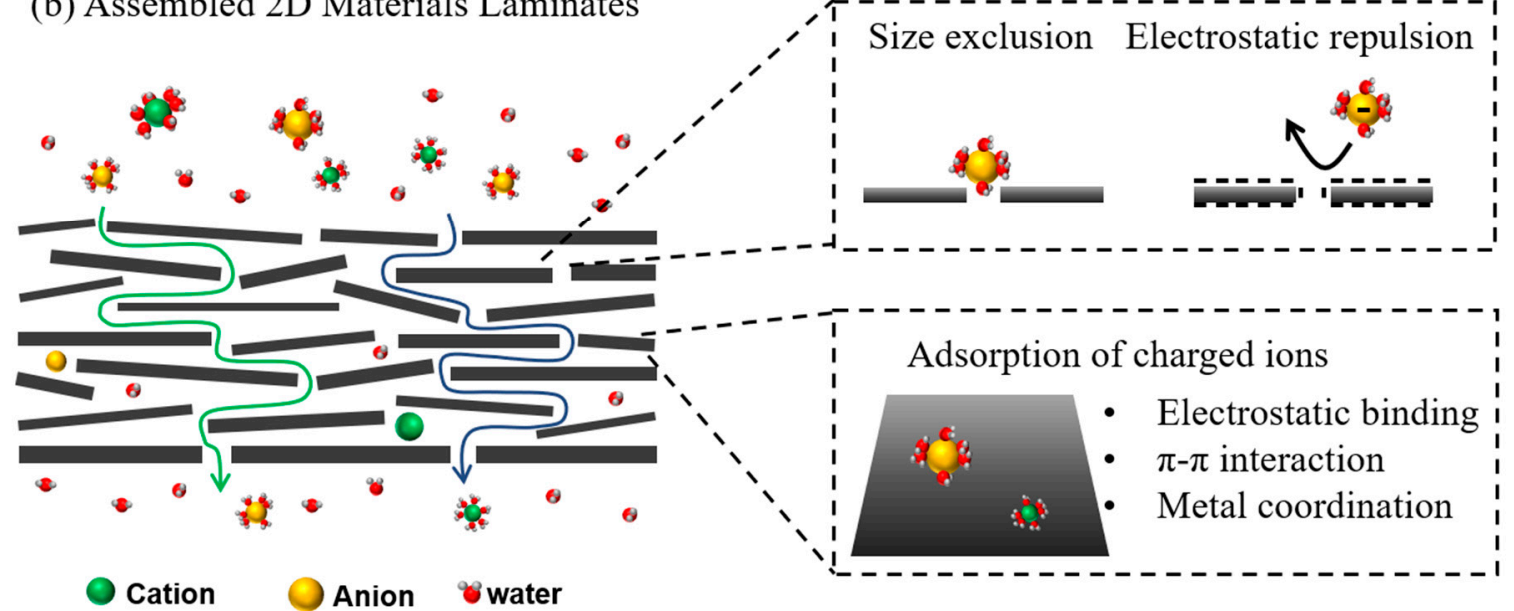

Figure 8. Schematic of the ionic transport mechanism of (a) a porous 2D material monolayer membrane consisting of nanopores of controlled pore size and $(\mathbf{b})$ assembled 2D material laminates resulting from stacked 2D nanosheets. The separation mechanism relates to size exclusion (pore size) and electrostatic interactions between the charged pores and ions. The arrows illustrate the direction of water molecules and charged ions through the membranes.

However, in terms of water permeability and leak-free fabrication, the scaling up to large-area membranes with precisely controlled pore densities and sizes still remains a significant technical challenge. One of the solutions to this challenge is the fabrication of alternative membranes based on the assembly of 2D materials (the laminar stacking of nanosheets) as shown in Figure 8b. This provides a well-ordered macroscopic structure, especially as the membranes formed from graphene oxide (GO) nanosheets are highly stackable due to their structure, which consists of a single-atom-thick layer with lateral dimensions (stacking up to tens of $\mu \mathrm{m}$ ). This stacking is enabled by the hydrogen bonds between each GO nanosheet from the oxygen-containing functional groups, which forms a durable and stable freestanding membrane $[85,86]$. In terms of low-cost production, GO nanosheets can be easily synthesized with a high-yield via the chemical oxidation and ultrasonic exfoliation of graphite which could potentially up-scale for use in industrial membranes.

\subsection{Ion Transport through Assembled 2D Materials Laminates}

Figure $8 \mathrm{~b}$ shows highly ordered films formed by the laminar stacking of the 2D nanosheets, demonstrating nanochannels from both adjacent and parallel graphene sheets $[56,87,88]$. On the basis of the stacking of nanosheets, these $2 \mathrm{D}$ nanochannels enable the permeation of 
water molecules while sieving ions that are larger in size than the channels. Moreover, the charge on the 2D nanosheets created by oxygen-containing functional groups on GO nanosheets provides active sites for the enhancement of ionic sieving due to electrostatic interaction [58,89]. These properties of laminar stacked membranes mean that 2D-based membranes represent ideal candidates for studies of ionic and molecular sieving membranes, in particular for seawater desalination (nanofiltration) [11,89] and energy harvesting (osmotic power or 'blue energy') $[9,10]$.

Based on typical ion transport within laminar membranes, size exclusion is the main factor of the separation mechanism, so the interlayer spacing of stacked 2D materials, especially GO sheets, plays a crucial role in the rejection. Due to the physical and chemical exfoliation of pristine graphite, GO sheets contain functional oxygen groups with an increased interlayer spacing from $3.4 \AA$ to $7-8 \AA$ due to hydrogen-bonding interaction between oxygen-containing groups within GO and water molecules $[56,90,91]$. Meanwhile, the interlayer spacing between GO sheets also increases with higher humidity, enlarging the spacing. For instance, the number of water layers in wet GO laminate is related to the interlayer separation. Wei et al. [92] calculated that the formation of mono-, bi-, and tri-layer water is associated with the interlayer spacing of $0.7,1.0$, and $1.4 \mathrm{~nm}$, respectively, for both graphene and GO.

Nair et al. [93] demonstrated that GO membranes allow excellent water permeation, with a rate estimated to be around $10^{10}$ times faster than helium permeation, but they also serve to sieve non-aqueous solvents such as liquids, vapours (acetone, hexane, and alcohols) and gases $\left(\mathrm{Ar}, \mathrm{H}_{2}, \mathrm{~N}_{2}\right.$, and $\left.\mathrm{He}\right)$. They proposed that this could be attributed to the low frictional flow of water molecules during transport through nanocapillary channels of closely packed graphene sheets, while other molecules become impermeable in low humidity situations through the narrower channels. GO membranes in a wet state allow the blocking of small solutes with a hydrated radius cut-off of around $4.5 \AA$, which allows small solutes $\left(\mathrm{K}^{+}, \mathrm{Na}^{+}, \mathrm{Cl}^{-}\right.$, and $\mathrm{Mg}^{2+}$ ) to pass through but blocks larger molecules (glycerol, $\left[\mathrm{Fe}(\mathrm{CN})_{6}\right]^{3-}$, and sucrose). The explanation suggested that a network of nanocapillary channels with a capillary-like high pressure exists inside the membrane, which allows particles smaller than the channels to penetrate through [94,95]. Due to the wrinkling and corrugation of the GO sheets by the oxygen-containing groups, this creates a network of capillary channels leading to the percolating regions of non-oxidized graphene (pristine regions), which is supported by velocity profiles for water flux between the graphene and the GO sheets $[92,96]$.

\subsection{Ion Transport Dependent Membrane Potential}

Membrane potential is defined as the electrical potential arising from the difference in ionic concentrations on each side of a semipermeable membrane. It is also known as transmembrane potential, and the phenomenon has been widely studied in biological cell membranes such as neurons and muscle cells. The application of an electric field across the membrane allows us to determine the charge and size selective ion sieving through the nanoporous graphene (NPG) membranes [97], angstrom-scale slits [69] and laminar stacked 2D membranes [9-11,56]. The principle of membrane potential will be discussed in this section in the context of the model used.

In general, the difference in ionic concentration on either side of a semipermeable membrane encourages the flow of ions from the high concentration to the low concentration area via diffusion process. The negatively charged membrane (cation-exchange membrane; CEM) allows cationic species to pass through the membrane rather than anionic species $(\rightarrow$ symbol in Figure 9a). This process leads to uncompensated anions and uncompensated cations in the feed and the permeate sides, respectively. Because of these uncompensated charges, ions accumulate on the membrane surface, leading to a separation of charges. This causes an electric field to be generated within the membrane (the $\leftarrow$ symbol in Figure 9a), which creates forces that oppose the flow of ions through the membrane. The point at which the force of the electric field balances the force of diffusion is called the equilibrium 
potential, and the net flow of the specific ion at this point is zero [1,98]. This process can occur when the membrane is capable of selective permeability by one or more ions.

(a) Transmembrane potential

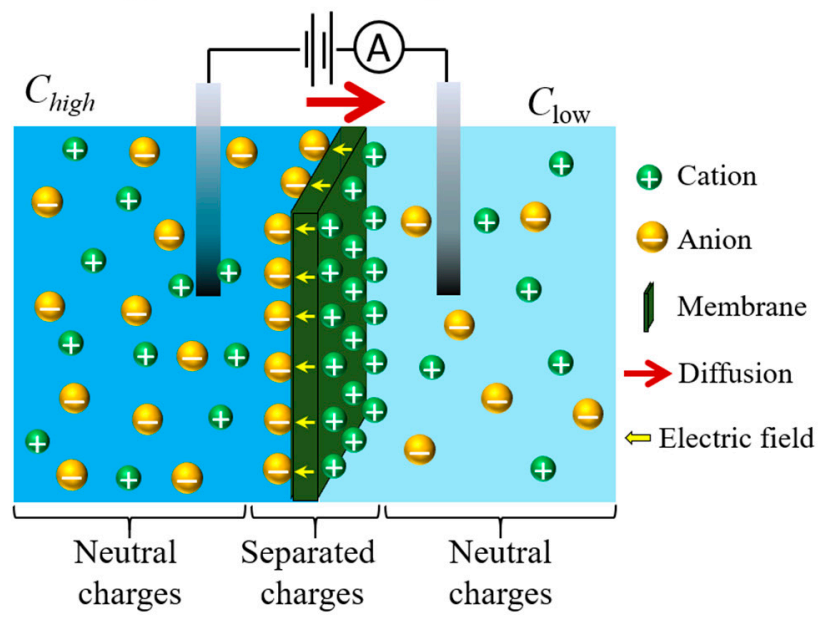

(b) Constant-field assumption

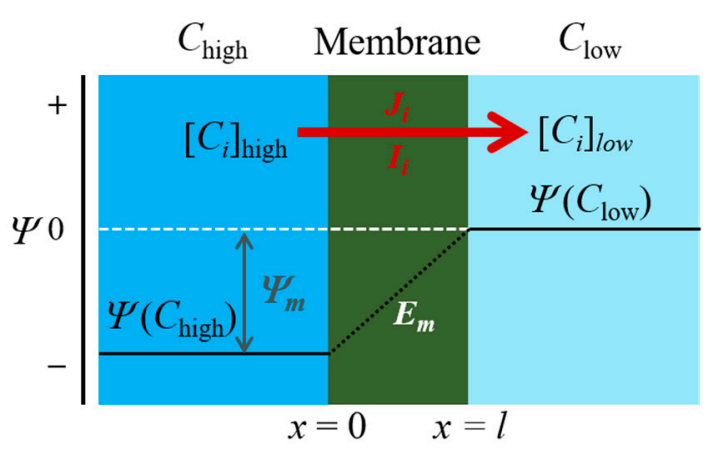

Figure 9. (a) Schematic of ion transport through a semipermeable membrane (a cation-exchange membrane in this example) showing the difference in ion concentration between two liquid reservoirs separated by the membrane. The red and yellow arrows represent the diffusion force and migration direction within the membrane, respectively. (b) Electrodiffusion model in the membrane illustrating the constant field assumption. According to Goldman's Assumption, the electrical field is the same at all positions along the membrane thickness $(d E / d x=$ constant). The field is the electric potential difference between two liquid reservoirs $\left(E_{\text {permeate }}-E_{f e e d}\right)$ through the membrane thickness $(l)$. The flow of ions $(i)$ across a semipermeable membrane is related to a molar flux $\left(J_{i}\right)$ and electric current density $\left(I_{i}\right)$. The ionic concentration and the electric potential in the membrane are $C_{i}$ and $E_{m}$ respectively. Note the reduced potential $(\Psi)$ is $\Psi=F E_{m} / R T$.

The Nernst equation is used to determine the equilibrium state of the membrane when the membrane is permeable to only a single type of ion. However, if several types of ions on both sides are involved in the flow through the membrane (i.e., the membrane is permeable to various ions) then membrane potential can be evaluated using the Goldman-HodgkinKatz (GHK) equation, which allows the selective determination of ion. This equation is an extended version of the Nernst equation.

Based on the assumption of the GHK equation [99,100], the electrodiffusion model is used to assume the flow of an ion through the membrane, which is associated with various conditions. The conditions considered are based on a homogeneous slab of material (one that is uniform, planar and infinite in its lateral extent), a constant electric field (the potential decreases linearly within the membrane), a material in which ions can move across the membrane independently (without interacting with one another), and have constant permeability, $P$, (where $P=\beta D / l ; \beta, D$, and $l$ are the partition coefficient, the diffusion coefficient, and the membrane thickness, respectively) [1,100-102]. In this assumption, the $x$-axis is used to represent the direction of the flow of ions through the membrane. Thus, the origin of the flow lies at the interface of the membrane on the feed side (denoted $x=0$ ) and its termination is the interface of the membrane at the permeate side (denoted $x=l$ ) when the membrane thickness is $l$, as shown in Figure $9 \mathrm{~b}$. As the membrane is assumed to have lateral uniformity, variations in the electric field $\left(E_{m}\right)$ and ionic concentration $\left(C_{i}\right)$ within the membrane are related only to the $x$-direction. The assumption under the GHK model is that the field inside the membrane is constant and equal to:

$$
\frac{d E}{d x}=\frac{E_{p}-E_{f}}{l}=\frac{-E_{m}}{l}
$$

where $E_{m}$ is the transmembrane voltage, $E_{p}$ and $E_{f}$ are the potential at the permeate and feed sides of the membrane surface, respectively. 
To determine ion selectivity across the membranes, the GHK equation as derived from the Nernst-Planck equation was used [99,100,102]:

$$
\begin{gathered}
I_{i}=\frac{P_{i} z_{i}^{2} F^{2} E_{m}}{R T} \frac{\left[C_{i}\right]_{f}-\left[C_{i}\right]_{p} \exp \left(z_{i} \frac{F E_{m}}{R T}\right)}{1-\exp \left(z_{i} \frac{F E_{m}}{R T}\right)} \\
I_{\text {total }}=I_{+}+I_{-}
\end{gathered}
$$

where $I_{i}$ is the ionic current density of the cation $(i=+), I_{\text {total }}$ is the total current density across the membrane, $P_{i}$ is the permeability of the ion $i, E_{m}$ is the membrane potential, and the other symbols have their usual meanings. $E_{m}$ can be obtained from the zerocurrent potential. The ionic current density is calculated from the ionic current, where the effective membrane area of the membrane is calculated from the geometric mean of the inlet and outlet aperture areas of the membranes. This means that the flow of ions through the membrane involves three main factors: the membrane permeability $\left(P_{i}\right)$, the ionic concentration gradient on either side of the membrane $\left(\left[C_{i}\right]_{f} /\left[C_{i}\right]_{p}\right)$, and the potential across the membrane.

According to solubility diffusion theory, ion permeability is typically governed by the solubility and diffusion coefficient of the species in the membrane, $P_{i}=\beta D_{i} / l$. The Nernst-Einstein relationship means that ion mobility is related to the diffusion coefficient, $D_{i}=R T \mu_{i} / F$. Hodgkin and Katz proposed the concept that membrane permeability relates to ion mobility $\left(\mu_{i}\right)$ within the membrane, the partition coefficient $(\beta)$, and the membrane thickness $(l)$, as shown in Equation (15):

$$
P_{i}=\frac{R T \mu_{i}}{F} \frac{\beta}{l}
$$

Using Equations (13)-(15), the mobility ratio between cations and anions $\left(\mu^{+} / \mu^{-}\right)$ can be deduced from the membrane potential $\left(E_{m}\right)$ where different potential gives the zero-current $\left(E_{m}\right.$ at $I_{+}+I_{-}=0$, the zero-current potential):

$$
\frac{\mu^{+}}{\mu^{-}}=-\frac{\mathrm{z}_{-}^{2}}{\mathrm{z}_{+}^{2}}\left(\frac{\left[\mathrm{C}^{-}\right]_{f}-\left[\mathrm{C}^{-}\right]_{p} \exp \left(\mathrm{z}_{-} \frac{F E_{m}}{R T}\right)}{\left[\mathrm{C}^{+}\right]_{f}-\left[\mathrm{C}^{+}\right]_{p} \exp \left(\mathrm{z}_{+} \frac{F E_{m}}{R T}\right)}\right)\left(\frac{1-\exp \left(\mathrm{z}_{+} \frac{F E_{m}}{R T}\right.}{1-\exp \left(\mathrm{z}_{-} \frac{F E_{m}}{R T}\right.}\right)
$$

where $\left[\mathrm{C}^{+}\right]_{f}$ and $\left[\mathrm{C}^{-}\right]_{p}$ are the concentration of cations and anions in the feed and permeate sides, respectively, and $z_{+}$and $z_{-}$are the valences of the cations and anions, respectively. The drift-diffusion experiment can be performed to obtain the zero-current potential, which is driven by the concentration gradient and the applied electric field. Thus, Equation (16) can be widely used to determine the influence of charge and ion size during transport as well as ionic sieving inside the membranes.

To apply in real-world membrane applications (for example, water electrodialysis, desalination, and energy conversion technologies), the use of semipermeable membranes can be further applied for energy production from salinity gradients. This is called osmotic energy ('blue energy'), which arises from the difference in chemical potential between higher and lower concentrations of salts $[2,103,104]$. The energy produced is a renewable energy alternative that is clean, sustainable, and abundant energy, which the process can occur naturally at any estuaries. Due to the challenges for energy-harvesting technology, the novel membrane materials i.e., 2D nanoporous membranes and laminar 2D-based membranes possessing extraordinary size and charge selectivity can be used to harvest future energy conversion. For example, large osmotic current energy in a salt concentration gradient can be produced form the membrane materials such as boron nitride nanotubes [105], porous 2D monolayer membranes (e.g., $\mathrm{MoS}_{2}$ ) $[57,106,107]$, and graphene-based membranes $[28,108]$. These indicate that various 2D materials (both porous 2D material layer 
and assembled 2D materials laminates) could be potential to implement as membranes for blue energy harvesting under salinity gradient.

\section{Stimulus-Responsive Microsupercapacitors and Their Applications}

Ion transport technologies have important applications for miniaturized energystorage components, including microbatteries and microsupercapacitors. Due to high power densities and long lifetimes, microsupercapacitors have been investigated at length as miniaturized energy-storage components in wearable gadgets and self-powered wireless sensor networks found in applications such as implantation biosensors, patient monitoring, environmental monitoring and national security [109,110]. Microsupercapacitors can be categorized into two configurations, namely stacked and in-plane interdigitated configurations (Figure 10) [109].

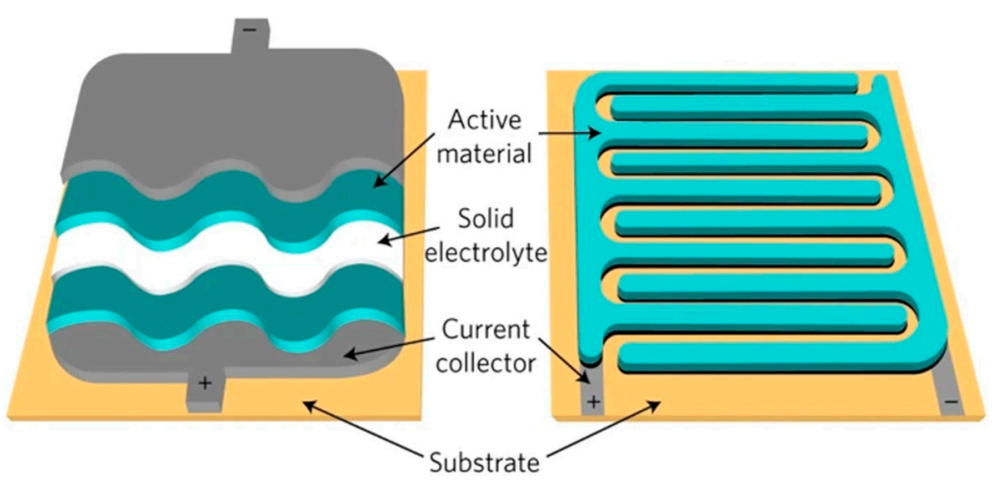

Figure 10. Schematic illustration of the configurations of microsupercapacitors. Left: stacked configuration. Right: in-plane interdigitated configuration. Reprinted by permission from Macmillan Publishers Ltd.: nature nanotechnology (ref. [109]), copyright (2017).

In the stacked configuration, two electrodes are separated vertically with respect to the substrate plane. However, in the in-plane configuration, both electrodes, which typically have an interdigitated shape, are separated horizontally on the substrate plane. The advantages of the in-plane configuration are ease of fabrication and flexibility to adjust and control a geometry of electrodes via conventional lithography techniques such as photolithography [111]. Decreasing the distance between each pair of interdigitated electrodes can enhance power densities due to the shortened ion transport path [112-114]. The in-plane interdigitated configuration also allows easy integration with other on-chip microelectronic devices that are facilitated by an in-plane electrical connection [112]. The configuration is also compatible with all types of electrolytes in both solid and liquid form [111]. Moreover, as the sides of the interdigitated electrodes are exposed to the electrolyte, the effective surface area increases, resulting in an increase in capacitance [111].

Although microsupercapacitors with in-plane interdigitated configuration have been intensively researched for on-chip energy storage [112,115-118], exploration of their use for novel functionalities is still in an early stage. Over the past five years, researchers have gained increased attention through their investigation of such functionalities for novel applications, such as direct visualization of the energy storage state [119], light-induced energy storage and photodetection [120] and ion transport control [31]. These functions are enabled by the stimulus-responsive behavior of the microsupercapacitors, in which properties such as color and capacitance can be tuned via an external stimulus $[31,119,120]$. In the following sections, we will show how the stimulus-responsive microsupercapacitors can be used in those applications.

\subsection{Direct Visualization of Energy-Storage States}

The first stimulus-responsive microsupercapacitor with in-plane interdigitated configuration was reported by Zhang et al. in 2017 [119]. A stimulus-responsive mechanism 
is based on a reversible electrochromic effect, in which the color intensity of the electrochromic material can be tuned by an external voltage, enabling potential applications in the direct visualization of energy storage states [119]. The microsupercapacitor consists of interdigitated electrodes made from exfoliated graphene (EG) $/ \mathrm{V}_{2} \mathrm{O}_{5}$-nanoribbon hybrid film and PVA/ $\mathrm{LiCl}$ gel electrolyte dissolved in methyl viologen $\left(\mathrm{MV}^{2+}\right)$ to allow electrochromic function [119]. Figure 11a shows the fabrication process of the microsupercapacitor [119]. The $\mathrm{EG} / \mathrm{V}_{2} \mathrm{O}_{5}$ hybrid film was prepared using the vacuum filtration method, and the film was then transferred onto glass or flexible polyethylene terephthalate (PET) slide, followed by the thermal deposition of a $60 \mathrm{~nm}$ Au layer through a shadow mask. Subsequently, the uncovered areas of the $\mathrm{EG} / \mathrm{V}_{2} \mathrm{O}_{5}$ film were removed by $\mathrm{O}_{2}$ plasma and $\mathrm{HCl}$ solution to create the channels for interdigitated electrodes, followed by drop casting and the solidification of the viologen dissolved PVA/LiCl gel electrolyte.

The microsupercapacitor delivered an area capacitance of $3.92 \mathrm{mF} \mathrm{cm}{ }^{-2}$ at $10 \mathrm{mV} \mathrm{s}^{-1}$. Figure 11c shows the change in color of the electrode caused by the electrochromic effect during charge-discharge cycles between 0 and $1.0 \mathrm{~V}$. The electrons and ions are injected into and removed from the viologen during the charge/discharge cycles, resulting in a change of color from colorless $\left(\mathrm{MV}^{2+}\right)$ to purple $\left(\mathrm{MV}^{+}\right)$, as shown in Figure $11 \mathrm{~b}$. The response time for the electrochromic effect decreases as the density of the current increases, ranging from several minutes to a few seconds at the current densities from 0.01 to $0.4 \mathrm{~mA} \mathrm{~cm}^{-2}$. Figure $11 \mathrm{~d}$ shows the UV-VIS spectra of the microsupercapacitor during one charge/discharge cycle, showing that the absorbance and thus the transparency of the color varies according to the voltage applied. In addition, Figure 11e illustrates that the normalized absorbance at $550 \mathrm{~nm}$ increases approximately from 0.75 at $0 \mathrm{~V}$ to 1 at $1.0 \mathrm{~V}$, translating to approximately $25 \%$ absorbance upon the applied voltages between 0 and $1.0 \mathrm{~V}$. This phenomenon can potentially benefit applications in the direct visualization of energy storage states without the aid of extra techniques [119].

However, as Figure 11d shows, it is only the spectrum intensity that changes under different applied voltages. It has been demonstrated that the integration of metal nanoparticles with electrochromic material offers a new functionality to the microsupercapacitor, namely wavelength tuning via a combination of plasmonic and electrochromic effects [121,122]. The nanoparticles readily absorb light at plasma frequencies which is directly proportional to the square root of the free carrier concentration in the metal [121,123]. Metals are typically used as a plasmonic material for applications in the visible spectrum due to high plasma frequency, which exhibits a high absorption peak at a specific wavelength (referred to as the resonance wavelength) in the visible region [121,122].

Hopmann et al. demonstrated a wavelength modulation based on the plasmonic effect in gold nanocavities as well as an electrochromic effect in tungsten oxide $\left(\mathrm{WO}_{3}\right)$ [122]. The device shows a broad peak resonance wavelength shift of $64 \mathrm{~nm}$, resulting in a variety of colors at different applied current densities (Figure 12a,b). These applied current densities cause a change in the refractive index of the electrochromic material induced by the insertion and removal of electrolyte ions during charge and discharge cycles, resulting in a shift of resonance wavelength and thus a change in colors $[121,122,124]$. This phenomenon opens up exciting potential applications such as tunable spectral filters and tunable displays. Unfortunately, the combination of the plasmonic and electrochromic effects has not yet been employed in microsupercapacitors with in-plane interdigitated configurations. It would be interesting to perform such an experiment, as it should enable ultrafast tunable spectral filters and color-switchable displays. 
(a)

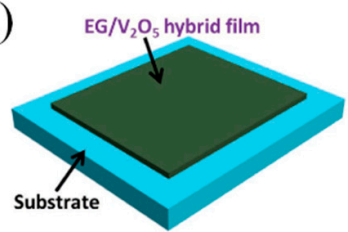

(i) Masking and depositing Au Substrat

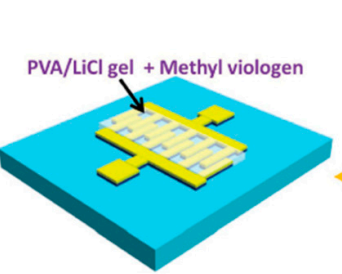

(iv) Electrolyte, methyl viologen

(v) Solidification

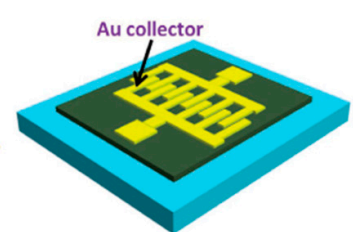
(iii) $\mathrm{HCl}$ solution plasma etching

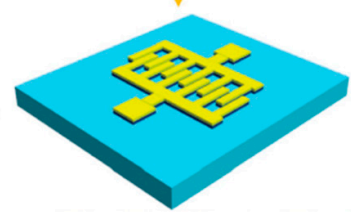

(b)

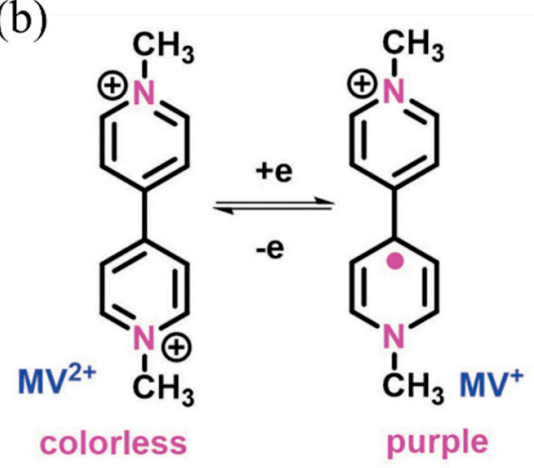

(c)
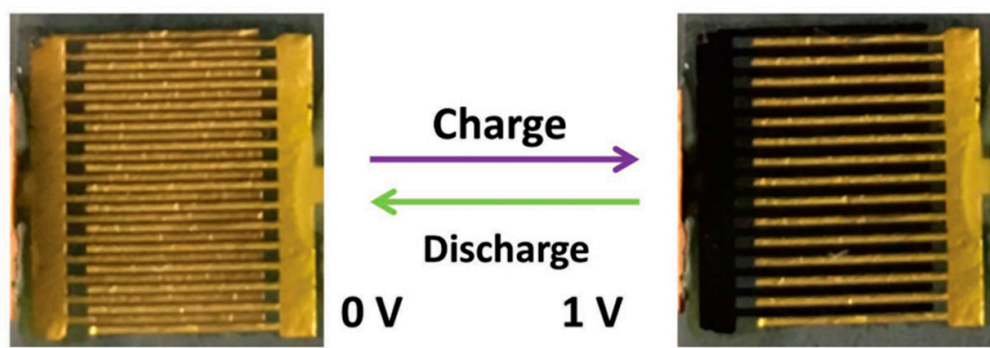

(d)

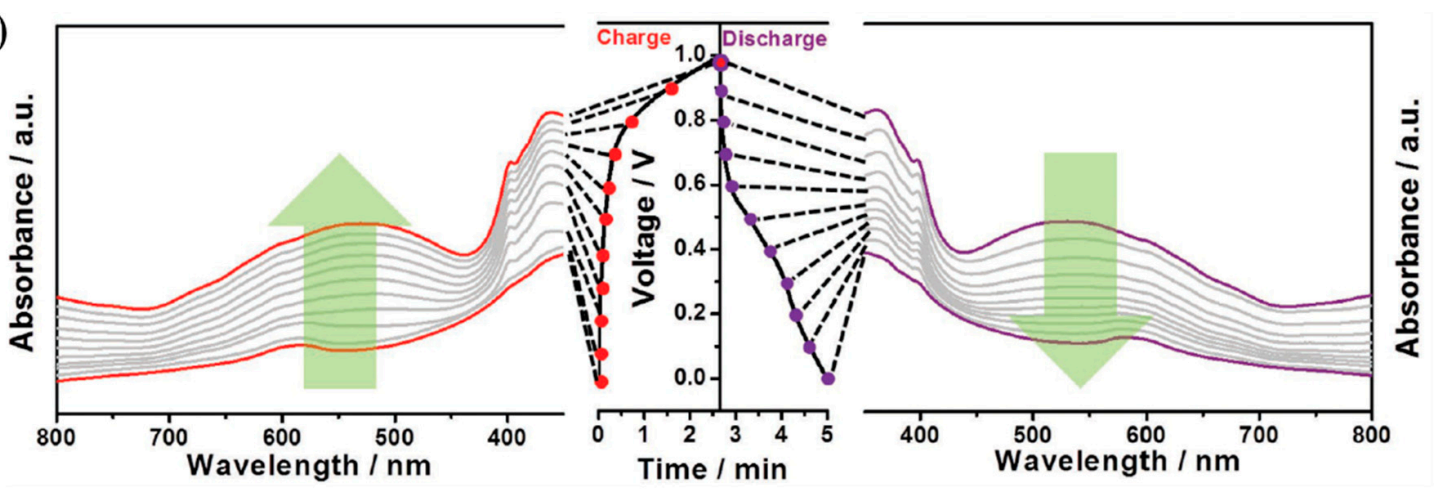

(e)

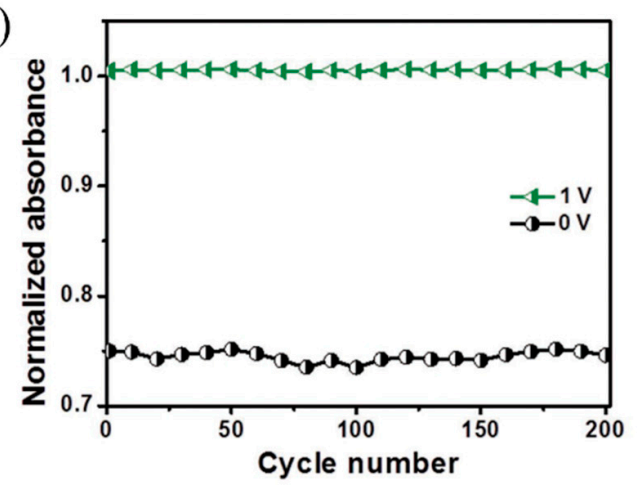

Figure 11. (a) The fabrication of an electrochromic microsupercapacitor with in-plane interdigitated electrodes. (b) The electrochromic mechanism of viologen. (c) Photographs of the reversible electrochromic effect of the microsupercapacitor during charge-discharge states. (d) The UV-VIS spectra of the electrochromic microsupercapacitor at different voltages at a current density of $0.015 \mathrm{~mA} \mathrm{~cm}^{-2}$ between 0 and $1.0 \mathrm{~V}$ during a single charge-discharge cycle. (e) Cycle stability of the electrochromic effect for the microsupercapacitor showing the voltage-controlled absorbance changes at $550 \mathrm{~nm}$ between 0 and 1.0 V. Reprinted with permission from ref. [119] Copyright (2016) Wiley. 
(a)

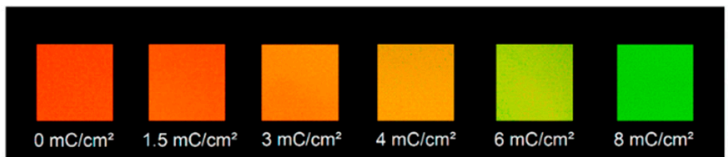

(b)

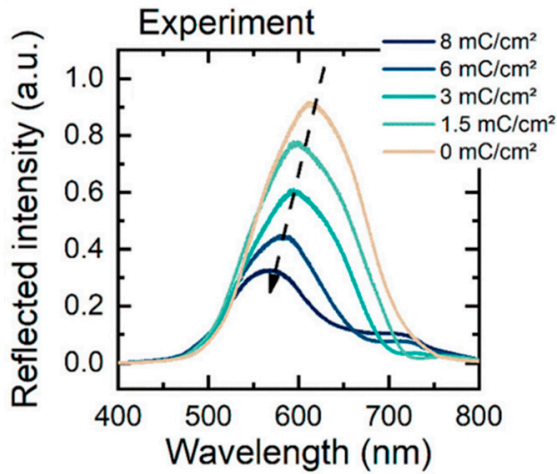

Figure 12. (a) $100 \mu \mathrm{m} \times 100 \mu \mathrm{m}$ raw images of reflected color at different applied current densities. Images are taken with a CMOS camera. (b) Experimentally obtained normalized reflectance at different charge densities. Reprinted with permission from ref. [122] Copyright (2020) American Chemical Society.

\subsection{Light-Induced Energy Storage and Photodetection}

Following the development of the first stimulus-responsive microsupercapacitor with an in-plane interdigitated configuration that was based on reversible electrochromic effect [119], Liu et al. developed the first photoswitchable microsupercapacitor with an in-plane interdigitated configuration by using light as the external stimulus [120]. The capacitance of microsupercapacitors can be tuned remotely using light illumination, enabling potential applications in remote-controlled energy storage and photodetection [120]. The fabrication process of the photoswitchable microsupercapacitor is similar to that of the electrochromic microsupercapacitor for a direct visualization of energy storage states developed by Zhang et al. [119], which is described in the previous section. Two layers of graphene grown using low-pressure chemical vapor deposition (LPCVD) were transferred onto a sapphire substrate, and a thin layer of diarylethene (DAE) molecules was spin-coated on top of the sample, forming a DAE-graphene composite film, before a 30nm $\mathrm{Au}$ layer was deposited onto the film through a shadow mask. Uncovered areas of the DAE-graphene composite film were subsequently removed using oxygen plasma to create the channels for interdigitated electrodes, followed by the drop casting of a thin layer of polymer gel electrolyte poly(vinyl alcohol) (PVA) $/ \mathrm{H}_{2} \mathrm{SO}_{4}$.

Figure 13a shows the dependence of the areal capacitance of the microsupercapacitor as a function of time under ultraviolet (UV) light at $366 \mathrm{~nm}$. We can see that before the exposure time of $400 \mathrm{~s}$, the capacitance increases almost linearly and then gradually becomes saturated after $400 \mathrm{~s}$. Using alternating illumination of UV and visible (VIS) light at an increment of $5 \mathrm{~min}$ (Figure 13b), the capacitance can be modulated by up to $20 \%$ [120]. This modulation is a consequence of the reversible photoisomerization of DAE in which the DAE isomer changes from DAE-O to DAE-C upon irradiation by UV light, and the reverse happens when the isomer is exposed to VIS light (Figure 13c). The mechanism behind the increase in capacitance under UV light illumination can be explained as follows [120]. The photoisomerization from DAE-O to DAE-C induces an interfacial charge transfer at the DAE-graphene interface, creating an interfacial dipole moment. This induces a downward shift in the lowest unoccupied molecular orbital (LUMO) level in DAE, leading to a reduction of the charge injection barrier for electrons into the LUMO orbitals of DAE molecules from the graphene electrode [120]. As a result, the capacitance increases. This phenomenon benefits applications for light-induced energy storage, such as remote-charging energy storage and remote capacitance modulation. In addition, because 
of the microsupercapacitor's sensitivity to UV light, it can be employed as a photodetector for visible/blind UV detection, including the detection of fire and missile plume [120].

(a)

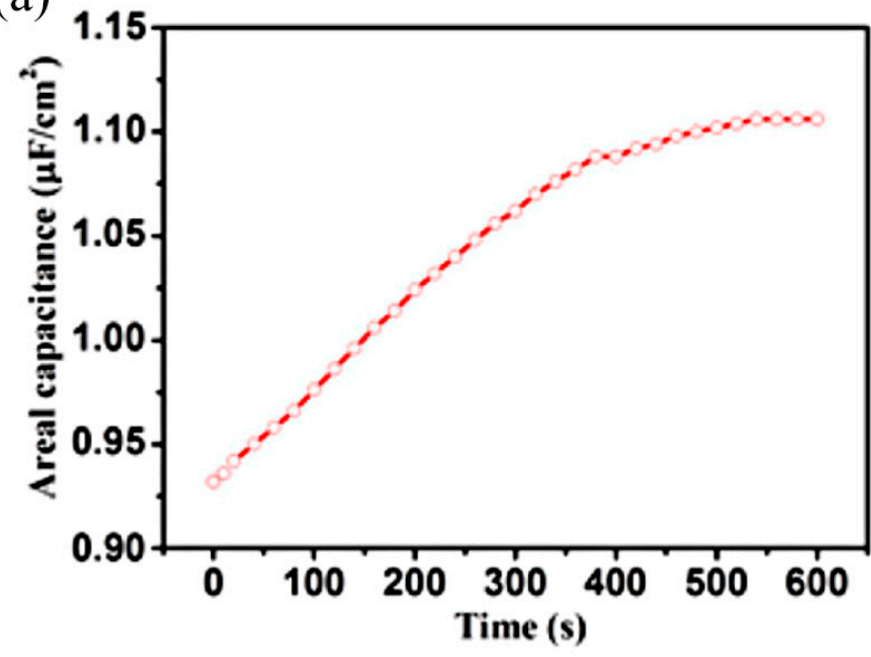

(b)

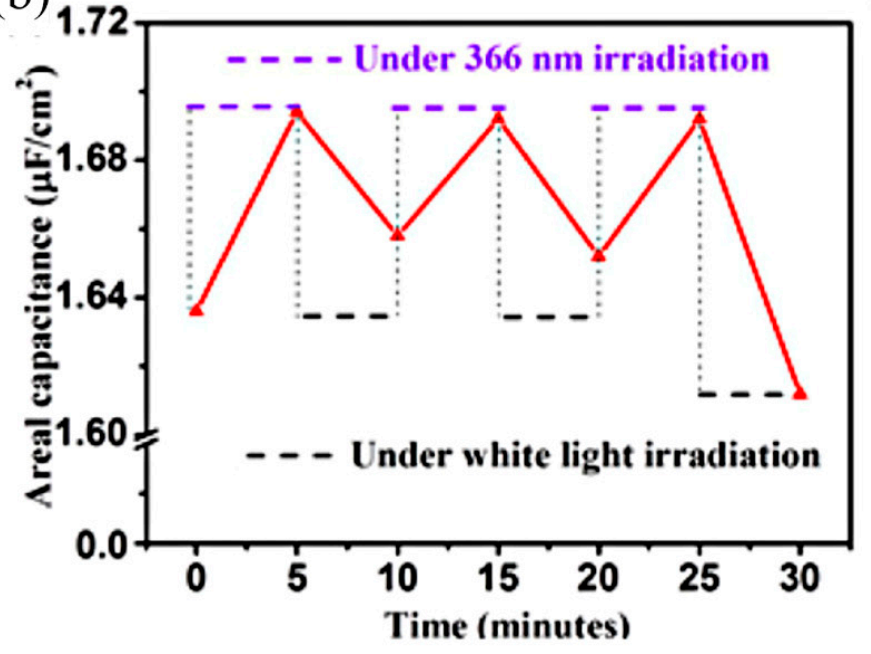

(c)

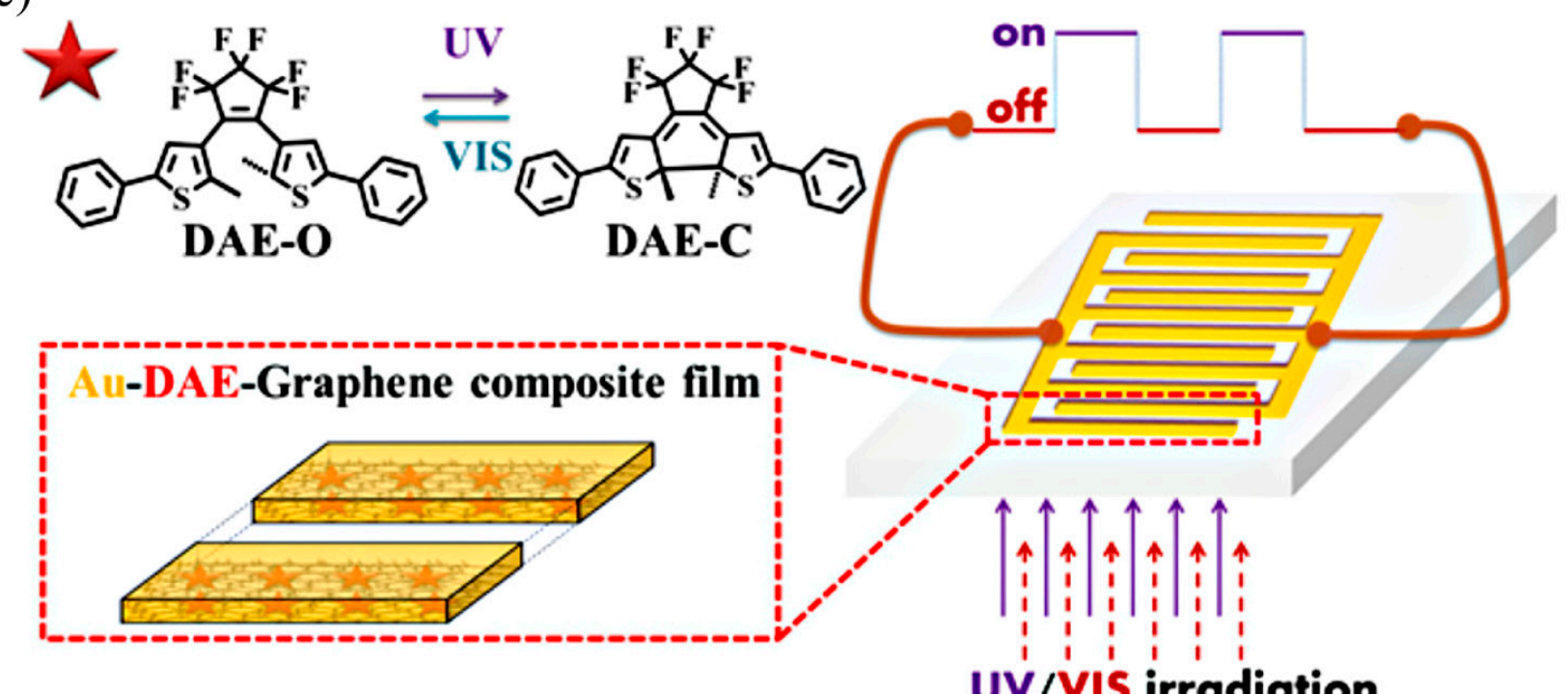

Figure 13. (a) Capacitance change of the DAE-graphene microsupercapacitor after different UV irradiation times. (b) On-off switching behavior of the DAE-graphene microsupercapacitor by alternating UV (366 nm) and white light (VIS) irradiations for a 5-min interval. (c) A schematic illustration of the photo-responsive DAE-graphene microsupercapacitor and its photoisomerization mechanism. Reprinted with permission from ref. [120] Copyright (2017) American Chemical Society.

Alternatively, under light illumination, the generation of electron-hole pairs in semiconducting materials could be used as a mechanism for capacitance modulation [125]. A semiconductor is widely employed as a light-absorbing material in photodetectors, where its long cut-off wavelength is determined by the energy gap between conduction and valence bands [126]. This wavelength limits the detection range of the photodetector, e.g., up to $1100 \mathrm{~nm}$ for a silicon photodetector [126]. The integration of a 2D material such as graphene with the silicon photodetector plays a crucial role in extending the detection range of the photodetector [127]. In addition, the heterostructure of different types of 2D materials such as graphene and rhenium disulfide $\left(\mathrm{ReS}_{2}\right)$ exhibits an excellent photo-responsivity of $7 \times 10^{5} \mathrm{~A} \mathrm{~W}^{-1}$ and a detectivity of $1.9 \times 10^{13}$ Jones, along with a fast response time of less than $30 \mathrm{~ms}$, which is promising for photodetection applications [128]. This can be attributed to the direct bandgap, the high quantum efficiency, strong light absorption 
by the multilayer $\mathrm{ReS}_{2}$ and the high carrier mobility of graphene [128]. A modulation of capacitance based on that mechanism, namely the generation of electron-hole pairs under light illumination, has been demonstrated by Arya et al. [125]. Multiple layers of $\mathrm{ReS}_{2}$ were grown on stainless steel using the chemical vapor deposition (CVD) method to serve as a working electrode. When light shines on this working electrode, electron-hole pairs are generated in the $\mathrm{ReS}_{2}$ separated by an electric field (Figure 14b). These additional charges increase the accumulation of electrolyte ions at the working electrode, leading to an increase in capacitance (Figure 14a). The process is reversible, with a 1.5-fold capacitance enhancement from $17.9 \mathrm{~F} \mathrm{~cm}^{-3}$ to $29.8 \mathrm{~F} \mathrm{~cm}^{-3}$ [125]. However, macroscale is a factor of this supercapacitor. It would be ideal if we could utilize $\mathrm{ReS}_{2}$ or another direct-bandgap semiconducting 2D material in the microsupercapacitor with in-plane interdigitated configuration in order to generate miniaturized ultrafast remote-charging energy storage and ultrafast remote capacitance modulation.

(a)

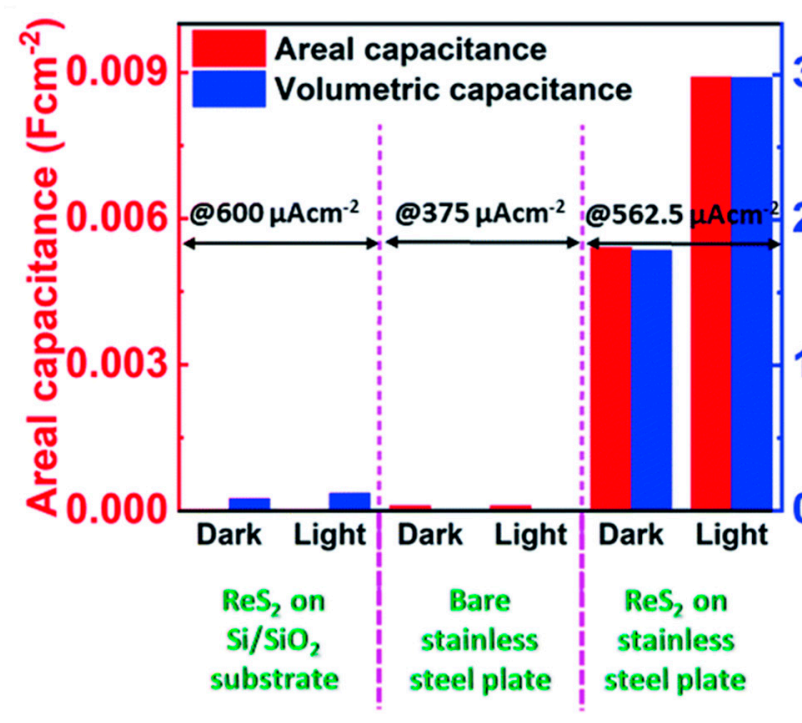

(b)

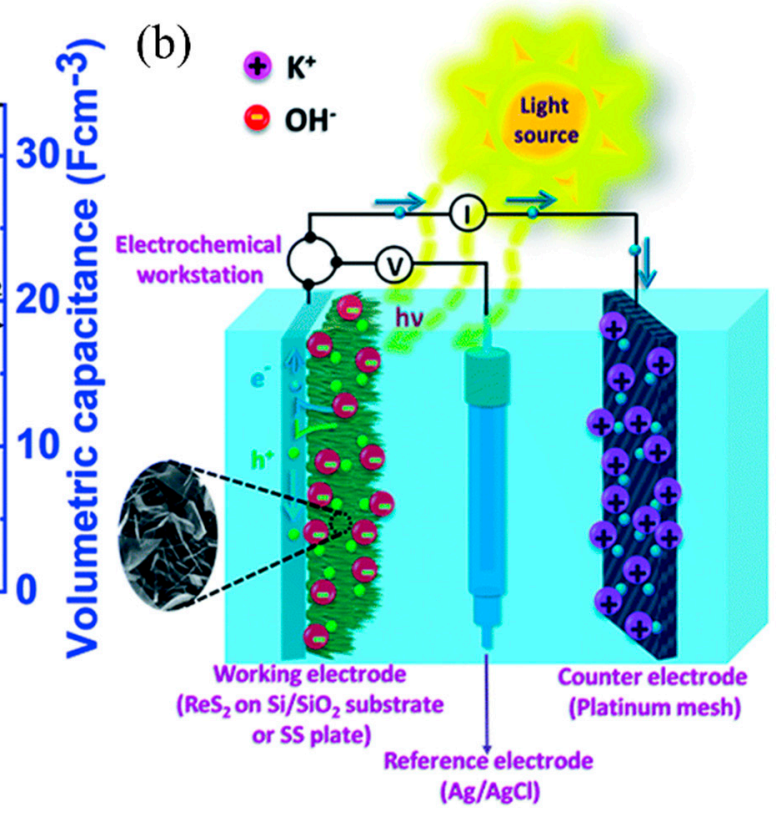

Figure 14. (a) The areal and volumetric capacitance of the supercapacitor under dark and light conditions. (b) Schematic illustration of the electron-hole pair generation under illumination. Reproduced from ref. [125] Copyright (2021) with permission from Royal Society of Chemistry.

\subsection{Ion Transport Control}

In 2020, Lochmann et al. developed the first switchable microsupercapacitor with inplane interdigitated configuration based on the architecture of a field effect transistor (FET), Figure 15a, with capacitance-tuning capability governed by the control of ion transport (Figure 15c) [31].

The microsupercapacitor consisted of two interdigitated electrodes, a gate electrode and a proton conducting PVA $/ \mathrm{H}_{2} \mathrm{SO}_{4}$ hydrogel electrolyte [31]. The interdigitated electrodes were fabricated using the advanced 3D-printing of a liquid carbon precursor solution onto a boron-aluminium silicate substrate, and they were contacted using silver conducting paste for capacitance measurements [31]. The gate electrode was produced by spin coating thin carbon film onto a silicon wafer. A $0.3 \mathrm{~mm}$ Kapton spacer was subsequently placed on top of the interdigitated electrodes to create a reservoir for electrolyte. The electrolyte was then applied into the reservoir and a gate electrode was placed on top. 
(a)

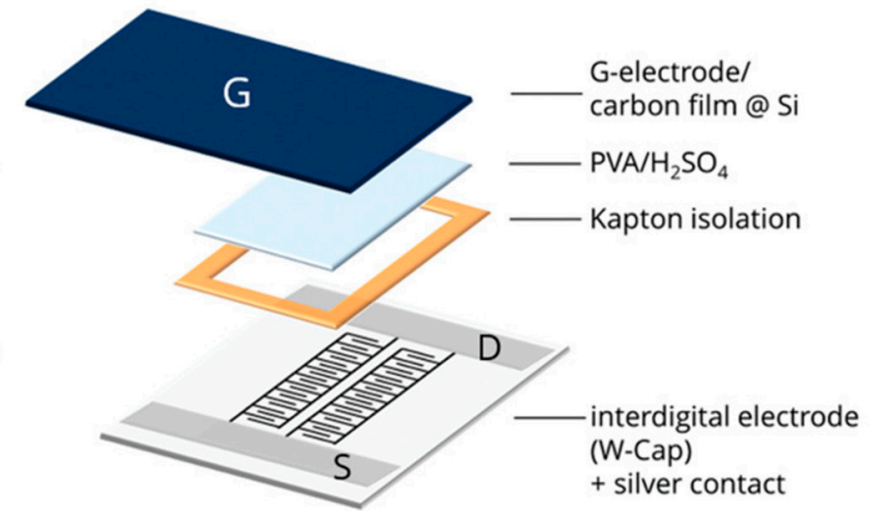

(c)

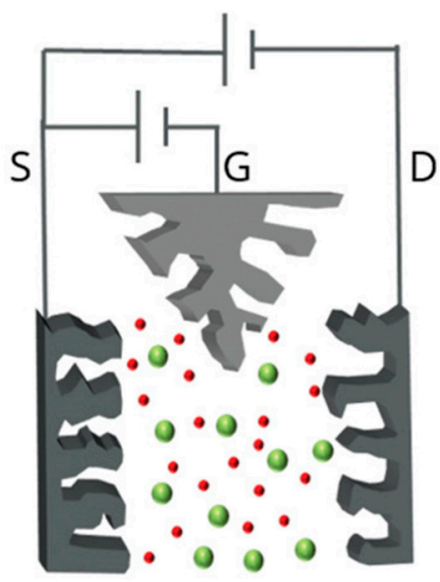

(b)
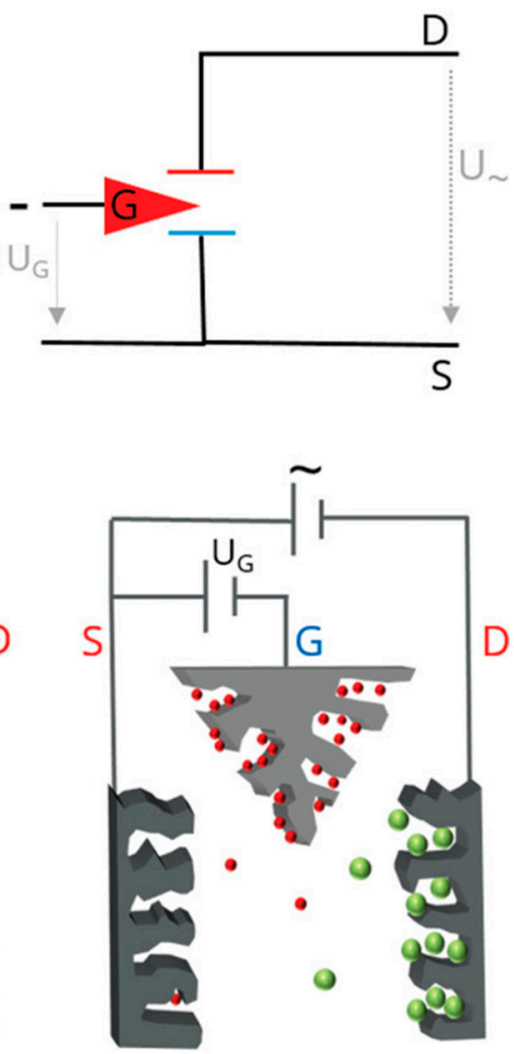

switched "off" (d)

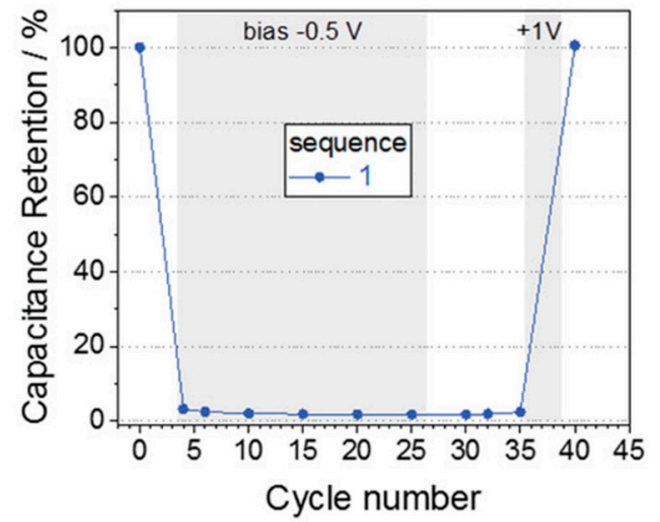

(e)

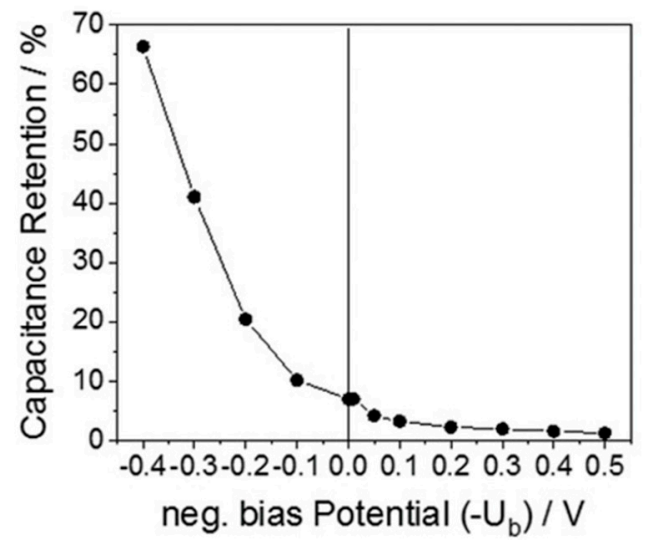

Figure 15. (a) Schematic showing the for the switchable microsupercapacitor with a field effect transistor (FET) configuration. (b) Electric circuit diagram. (c) A schematic illustration of the switching mechanism of the microsupercapacitor. (d) A plot of capacitance retention switching measured with $50 \mathrm{mV} \mathrm{s}^{-1}$ applying a gate voltage of $-0.5 \mathrm{~V}$ for the "off" state. (e) The capacitance-gating characteristics of the switchable microsupercapacitor. Reprinted with permission from ref. [31] Copyright (2020) Wiley.

Microsupercapacitors deliver a high on/off ratio of capacitance switching, in which capacitance drops from $100 \%$ capacitance retention in the "on" state to $1.8 \%$ capacitance retention in the "off" state (Figure 15d) [31]. In addition, Figure 15e shows that the capacitance retention is exponentially dependent on the gate voltage, which is comparable to a plot of the drain current versus the gate-source voltage in a field effect transistor (FET) [31]. Changes in capacitance come as a result of ion adsorption and desorption at the gate electrode. When the gate electrode is negatively biased (i.e., $-0.5 \mathrm{~V}$ ), the negative 
charges induce the adsorption of positive electrolyte ions. This adsorption reduces the number of positive ions inside the electrolyte and leads to a decrease in capacitance (the off state). The reverse occurs when applying a positive bias to the gate electrode (i.e., $+1 \mathrm{~V})$. This induces the desorption of positive electrolyte ions, pushing these positive ions back into the electrolyte and increasing capacitance accordingly (the on state). The ability to control the transport of ions can be beneficial for various ion-transport applications, including capacitive energy management, neuromodulation and ion transistor circuits [31].

The 3D interdigitated microsupercapacitor provides a large effective surface area $[111,117,118]$ which leads to an increase in capacitance within a small area [111]. Ferris et al. fabricated a microsupercapacitor with 3D interdigitated electrodes (Figure 16) by depositing pseudocapacitive hydrated ruthenium dioxide $\left(\mathrm{RuO}_{2}\right)$ onto highly porous Au current collectors on a 4 in. silicon wafer using a standard microfabrication technique [111]. The microsupercapacitor was encapsulated and tested using a PVA-based electrolyte doped with orthophosphoric acid $\left(\mathrm{H}_{3} \mathrm{PO}_{4}\right)$ and $\mathrm{SiWA}\left(\mathrm{H}_{4} \mathrm{SiW}_{12} \mathrm{O}_{40}\right)$, and was found to deliver excellent electrochemical performances with a capacitance per footprint area of $812 \mathrm{mF} \mathrm{cm}^{-2}$ at an energy density of $329 \mathrm{~mJ} \mathrm{~cm}^{-2}$, a result that can compete with Li-ion microbatteries [111]. It would be ideal to employ the interdigitated 3D electrodes in the switchable microsupercapacitor with the FET configuration to enhance the control of ion transport, which would be beneficial for the applications mentioned above.

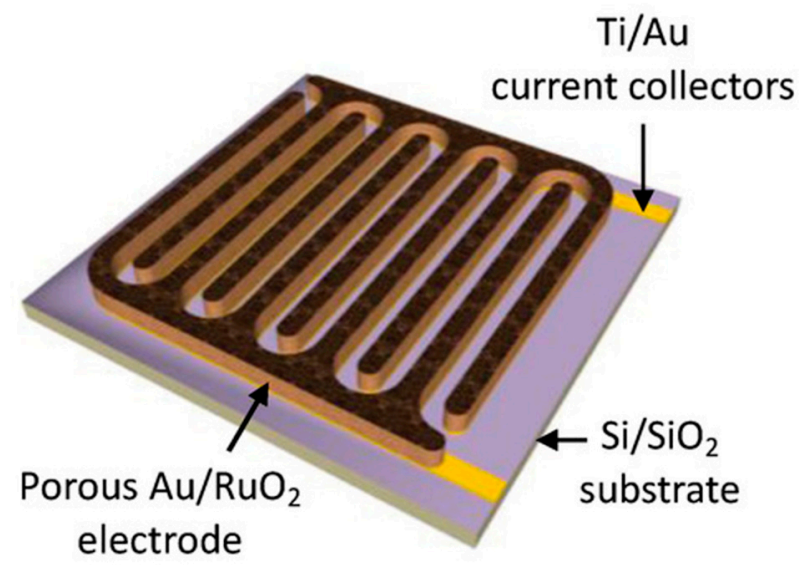

Figure 16. A schematic illustration of a microsupercapacitor with $3 \mathrm{D}$ porous $\mathrm{Au} / \mathrm{RuO}_{2}$ electrodes. Reprinted with permission from ref. [111] Copyright (2019) Wiley.

\section{Optical Induction with Ion Transport and Optical Techniques for Ion Transport}

The utilization of optical techniques for ion transport have recently become available through optical induction [129] and optical investigation [12], but fundamental mechanisms are more ambiguous. It is important to investigate these methods and the extension of boundaries further in biological simulation and manmade applications.

Ion transport can be defined using the diffusion relationship as ion diffuses via the diffusion layer in three dimensions, although the knowledge of diffusion in two dimensions is required. When ions diffuse on a 2D layer, their propagation is disrupted by the potential landscape of 2D materials. This potential landscape also relates to surface charge density, and this density can be induced by external and internal stimuli, including electric fields and photon energy $[130,131]$. Photo-induction will cause a surface charged redistribution which will affect the directional ion transport through optical and thermal influences $[32,33,132]$. Optical induction in nature can also be used to investigate living bacteria for active ion transport, and can also be utilized for nanomachine design for the harvesting of energy [2]. Light can not only be used for activated ion transport, but also for the visualization and tracing of ion and the molecular transport of cells. 


\subsection{Diffusive Behaviour of Ions on 2D Materials}

Ion transport takes place in 3-dimensional space, as discussed above. However, in specific channels and in confinement, ion transport can be assumed to behave in different dimensions; for example, in one dimension when translocating via narrow atomic channels such as nanotubes and nanopores, in two dimensions when travelling on membranes or between membrane sheets, such as nanoscale ion sieving applications, and in three dimensions when diffusing via a larger space, such as a microscopic channel or in higher dimensional diffusion (Figure 17a) [133].

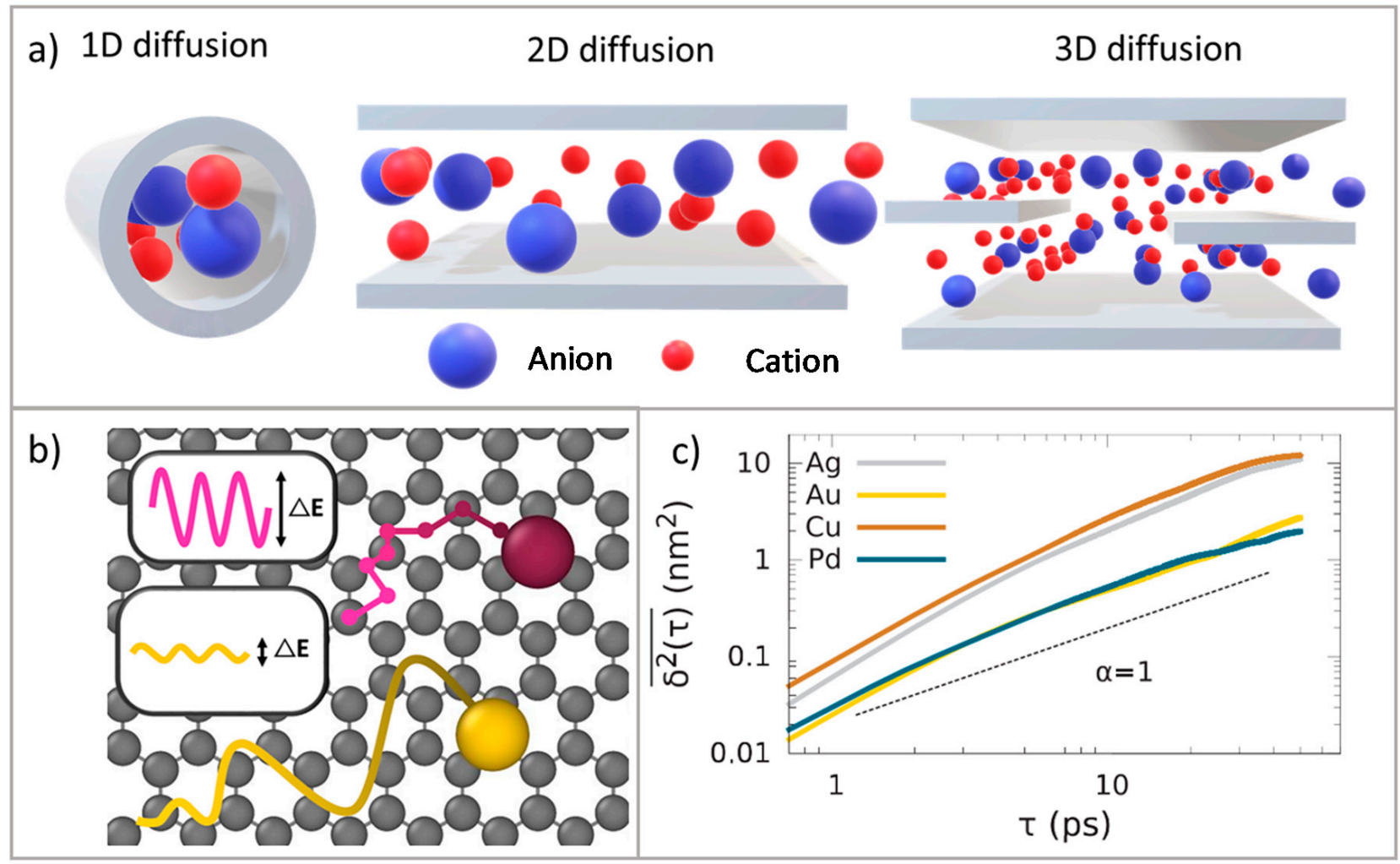

Figure 17. (a) Diffusion of ions in one, two and three dimensions due to boundary restrictions. (b) 2D diffusion of metal ions on graphene (purple shows diffusion with local potential restriction and yellow shows Levy walk behavior in a super-diffusive regime). (c) The relationship between the power law of mean square displacement $\left(\overline{\delta^{2}}\right.$ or $\left.\left\langle r^{2}\right\rangle\right)$ and the time steps $(\tau)$ of individual metal ions based on computational simulation [134]. Reproduced with permission from (a) ref. [134] Copyright (2020), American Chemical Society.

With potential wells and landscape prevention, diffuse ions can propagate to nearby regions with different diffusion regimes. Electrostatic activity and dehydration are the cause of potential landscape variation on 2D materials [135], so the consequences of internal and external stimuli can reveal the regime of ion diffusion. A diffusion equation (Fick's Law) can be used to represent diffusive behavior as normal or anomalous diffusion. Using the power coefficient, diffusion behavior on 2D materials can be justified by Equation (17) [136]:

$$
\left\langle r^{2}\right\rangle=4 D \tau^{\alpha}
$$

where $D$ is the diffusion coefficient, $\tau$ is a time constant, and $\alpha$ is the exponent. This relationship describes how particles propagate due to relative displacement and time step. If $\alpha=1$, the ion diffusion belongs to the normal diffusive regime, while if $\alpha<1$ it belongs to the sub-diffusive regime and if $\alpha>1$ it belongs to the super-diffusive regime. On a flat 2D surface, ions tend to be super diffusive due to potential landscape, crystal orientation and defects $[134,137]$. 
To enhance the effects of ion transport, the structural designs of 2D materials can be used to reengineer the ways in which ions propagate, with a significant jump in the super-diffusive regime $[134,138]$. When restricted by a 2D planar surface, the diffusion in normal and anomalous diffusion (the sub-diffusive and super-diffusive processes) is a quintessential property. Since our understanding of ion diffusion is a foundation of ion transport, few articles have studied the subject via simulation [134] or experiments [139].

Recently, the diffusion of metal ions was investigated in silico [134] using molecular dynamic (MD) simulation, including ab initio and classical molecular dynamics. The potential energy wells and landscapes of graphene $(0.004-0.188 \mathrm{eV})$ at room temperature (about $300 \mathrm{~K}$ ) provide the major roles, controlling the behavior of ion diffusion, whether the diffusions are normal or anomalous. The results showed normal diffusion behavior for $\mathrm{Pt}$ and $\mathrm{Ru}$ ions. However, an anomalous super diffusion was revealed on $\mathrm{Ag}, \mathrm{Au}, \mathrm{Cu}$ and $\mathrm{Pd}$, jumping across the potential landscapes (of $10 \mathrm{meV}$ potential difference with nm span) in the characteristic Levy walk (Figure 17b,c) [134]. This knowledge can be used for the future enhancement of ion transport.

Similar to super-diffusive ions on battery electrodes, the idea of $2 \mathrm{D}$ diffusion can be used to show that the influence of 2D diffusion can indicate different predictions of ion propagation through intercalated 2D materials, revealing a pseudocapacitive behavior when the diffusion period is less than $0.1 \mathrm{~s}$, when $D$ and $\left\langle r^{2}\right\rangle$ depend on the materials.

Recent comparisons of the performance of 2D materials against other materials as 2D electrodes for testing performance rates has been reported [140]. Different varieties of materials provide no obvious support for the efficiency of $2 \mathrm{D}$ materials. Based on the report, the electrode thickness $\left(L_{E}\right)$ is also a condition for material efficiency. When the electrodes related to charge/discharge time constant $(\tau)$ with exponent $(n)$ were investigated, it reveals the poorer rate performance of $2 \mathrm{D}$ materials when compared to non-2D materials. In addition, the rate of diffusion through stacked 2D materials was lower when compared with non-2D materials, because of the diffusion rate limitation on 2D material morphologies and a permeability of electrolyte in diffused channels. Using our knowledge of ion diffusion in batteries can improve our knowledge of ion transport capabilities and design in other ion transport related applications. The behavior of the $2 \mathrm{D}$ diffusion of ion also relates to variations in charge density [141] caused by external stimuli by electrochemical, photoelectrical, photothermal phenomena [142].

\subsection{Optical Induction in Ion Transport in 2D Materials}

Novel 2D materials are available with a wide range of applications. Because of their different crystalline structures and defects, these factors relate to specific band gap structures, of which some are suitable for optical absorption [143]. There have been reviews on the optical properties of 2D novel materials [143-145]. Bandgap energy properties and optical absorption for a whole spectrum span (Figure 18a) from insulators (e.g., hBN with $6 \mathrm{eV}$ bandgap in a range of UV absorption), semiconductors (e.g., TMDs, $\mathrm{MoS}_{2}$ with bandgap around 1.5-2.5 eV) are suited to visible light absorption in situations where black phosphorus occupies IR absorption with $0.3-2 \mathrm{eV}$ bandgap) and semimetals (e.g., graphene with no bandgap) [144].

Potential barriers represent restrictions to active transport. To lower these barriers, the membrane system needs to acquire additional energy to initiate ion transport. This additional energy can come in the form of pressure, chemical reagent, electrical bias, temperature or and photons $[32,33,132,139]$. Light can also be used to lower the potential barrier for ion transport on 2D materials and through porous membranes. The phenomena of optical induction on 2D materials is referred to as the photo-Dember effect [132] (Figure 18b). The photo-Dember effects involve charge redistribution due to higher photocarrier temperature. Despite the picosecond lifetime, photo-induction is a challenging topic for optoelectronic 2D materials. Among novel 2D materials, the photo-Dember effect on graphene is negligible when compared to electrical stimuli, but with the gradient involved 
in lateral photo-Dember effects, it produces a photocurrent signal showing responsive, nonequilibrium hot carriers [132].

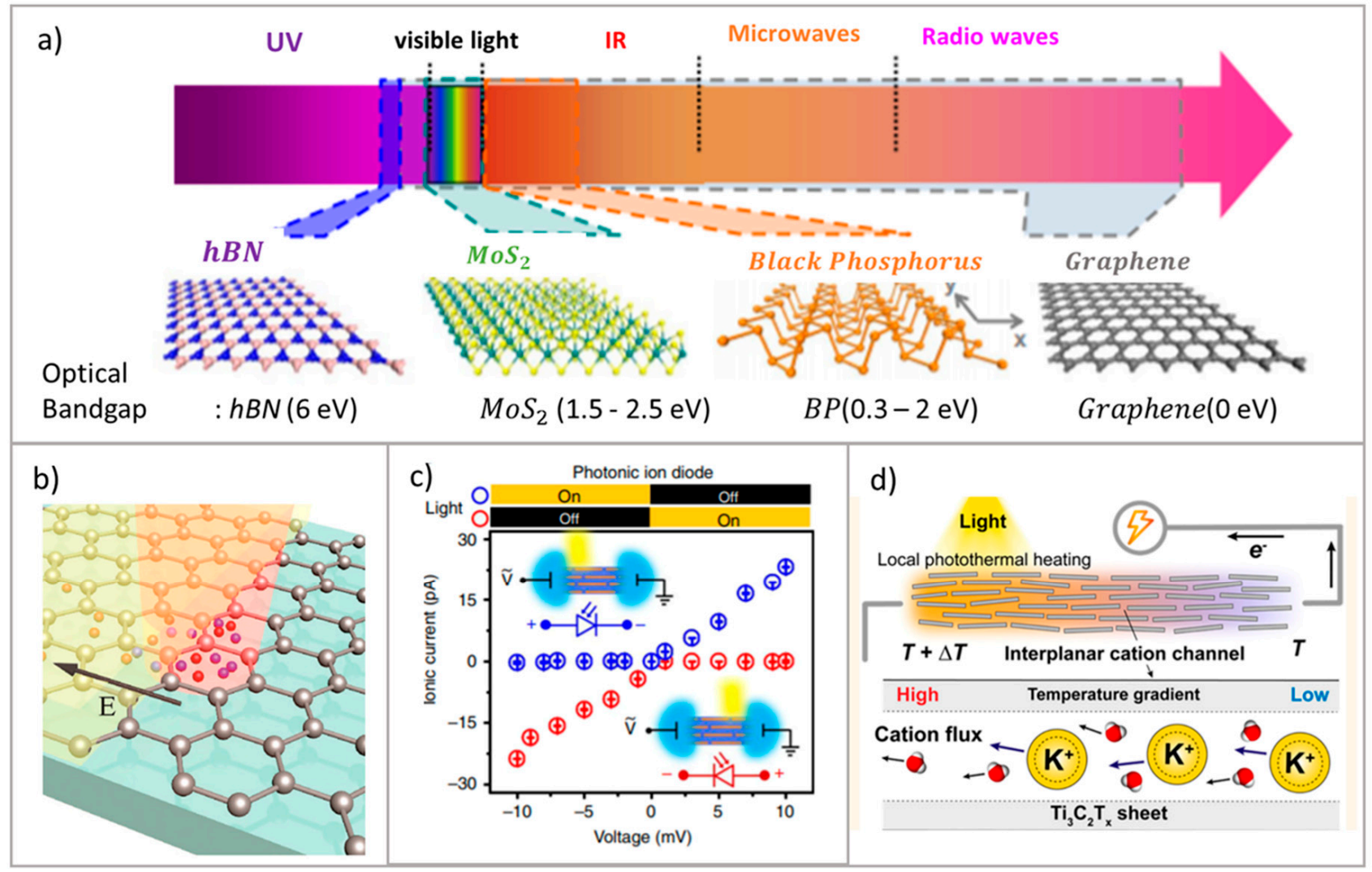

Figure 18. (a) 2D materials and optical bandgaps [144]. (b) Photo-Dember effect for increasing a local charge density [132]. (c) Photogate effect induces a directional ion transport via nanoscopic channels [32]. (d) Temperature gradient induces ion transport due to local charge density gradient [33]. Reproduced with permission from (a) ref. [144] Copyright (2014), Springer Nature; (b) ref. [132] Copyright (2014), American Chemical Society; (c) ref. [32] Copyright (2019), Springer Nature; (d) ref. [33] Copyright (2020), American Chemical Society.

Optical stimuli inducing the ultrafast active transport of ions also occurred in graphene oxide membranes. When asymmetric light is irradiated onto stacking graphene oxide membranes, anomalous and super diffusive ions are translocated against the ion concentration gradient. This can be applied to opto-electric devices, for example photonic ion diodes (Figure 18c), switches or transistors. The polarity of the diode, the on-off switch, and the current voltage of the transistor can be controlled by asymmetric light and its irradiated position on the graphene oxide membrane [32].

Although photoelectric stimuli occur for ion transport induction, responses from photothermal effects have also been investigated [33]. In stacking MXene nanochannels, the reduction of temperature of Gibbs free energy on light irradiated regions causes nonisothermal ion transport, shown in Figure $18 \mathrm{~d}$, with a response of up to $1 \mathrm{mV}$ per degree Kelvin. This also sheds light on photothermal ionic transport applications, which have the potential for $1.68 \mathrm{mWm}^{-2}$ output [33].

\subsection{Optical Induction in Ion Transport in Living Bacteria}

Ion transport is not only a phenomenon that is utilized in electronic devices, supercapacitors, and water purification applications [2]. In living cells, ion transport also plays a critical role for cell stabilization and adaptation to internal and external stimuli. In Eukaryotic [146] and Prokaryote cells (e.g., bacteria), the variation of membrane potentials 
related to ion transport on bacterial membranes can help identify the state and condition of bacteria. Membrane potentials can precisely indicate the health of bacterial cells [147,148].

Membrane potentials on bacterial membranes are due to the ion channels exchanging ions between the inside and outside of the cells, as happens in $\mathrm{Na}^{+}-\mathrm{K}^{+}$pumps. The variation of potential on membrane introduces ion transport on the membrane and influences the influx and efflux of other charges and ions that are transported through cell membrane. Some activity may require additional chemical energy in a form of adenosine triphosphates (ATPs) [149].

There are several forms of external stimuli on bacterial cells, including nutrient scarcity, environmental pressure, $\mathrm{pH}$, temperature and light or optical induction [147,150]. For optical induction in the active transport of living bacteria, ion transport proceeds through multiple steps with photoreceptor units or protein complexes. Charges can be transferred through bacterial membranes and onto bacterial membranes, as happens in 2D material investigation $[2,80]$. To mimic the behavior of living bacteria, the nanophotovoltaic model was created using photoinduction on the active membrane layer with ion selectivity, allowing ions to be transported to the osmotic membrane layer due to the non-active transport along the concentration gradient (Figure 19). This energy harvesting imitates from living bacteria [2].

Optical induction in living bacteria is challenging from an experimental perspective due to the speed of its process [151,152]. Using cutting-edge optogenetic technology, the femto-second transport of ions through complex pathways were reported. From the $\mathrm{Na}^{+}$ pump of the Krokinobacter eikastus system (KR2), the process of ion transport ranges from femto- to microseconds using time-resolved adsorption spectroscopy from crystalline KR2 [152], (Figure 19b).

Although light can be used for induced ion transport, it can damage and restrict cell proliferation due to phototoxicity [153]. As mentioned above, optical induction can induce charge distribution and activate the transport of active ions. However, light can also trigger reactive oxygen species (ROS), damaging cells and preventing cell proliferation. In Figure 19c, bacterial membrane potentials were investigated using fluorescent ThT reagents to indicate the state of cell polarization. When ROS were activated, UV irradiated cell became depolarized (the red color), while bacteria proliferation showed hyperpolarization (the blue color) [148]. The utilization of light induction for ion transport in living cell therefore requires optimization.

\subsection{Using Optical Fluorescence Techniques for the Investigation of Ion and Molecular Transport}

Since ion transport can be manipulated by optical induction, optical techniques can be used in addition to conventional electrical probing methods to trace ion transport, particularly fluorescence microscopy and spectroscopy. When ions are transported, they carry energy, which gives them the ability to activate fluorescent markers. To explore ion transport further, fluorescent markers such as dyes, quantum dots (QDs) and proteins are now available, and their use has been reported in various disciplines [154,155].

The utilization of electro-optic interaction indicates a state of electrical, ionic and charged molecule transport in living cells, moving from a comparatively simple to a more complex system, i.e., from the neuron surface [155] to a more heterogenous pathogenic bacterial surface [156]. In neuron cells, ions or carriers are transported, causing cell polarization due to the overall directional propagation of carriers. To investigate neuron cell polarization, Figure 20a shows the use of quantum dots to measuring ion transport response. The CdSe/CdS quantum dots (QDs) showed red shift behavior when sensing different potentials from 0 to $0.9 \mathrm{MV} / \mathrm{cm}$ [157]. With this QDs tracing, ion transport on neuron cell can be measured in sub-milliseconds [155]. 


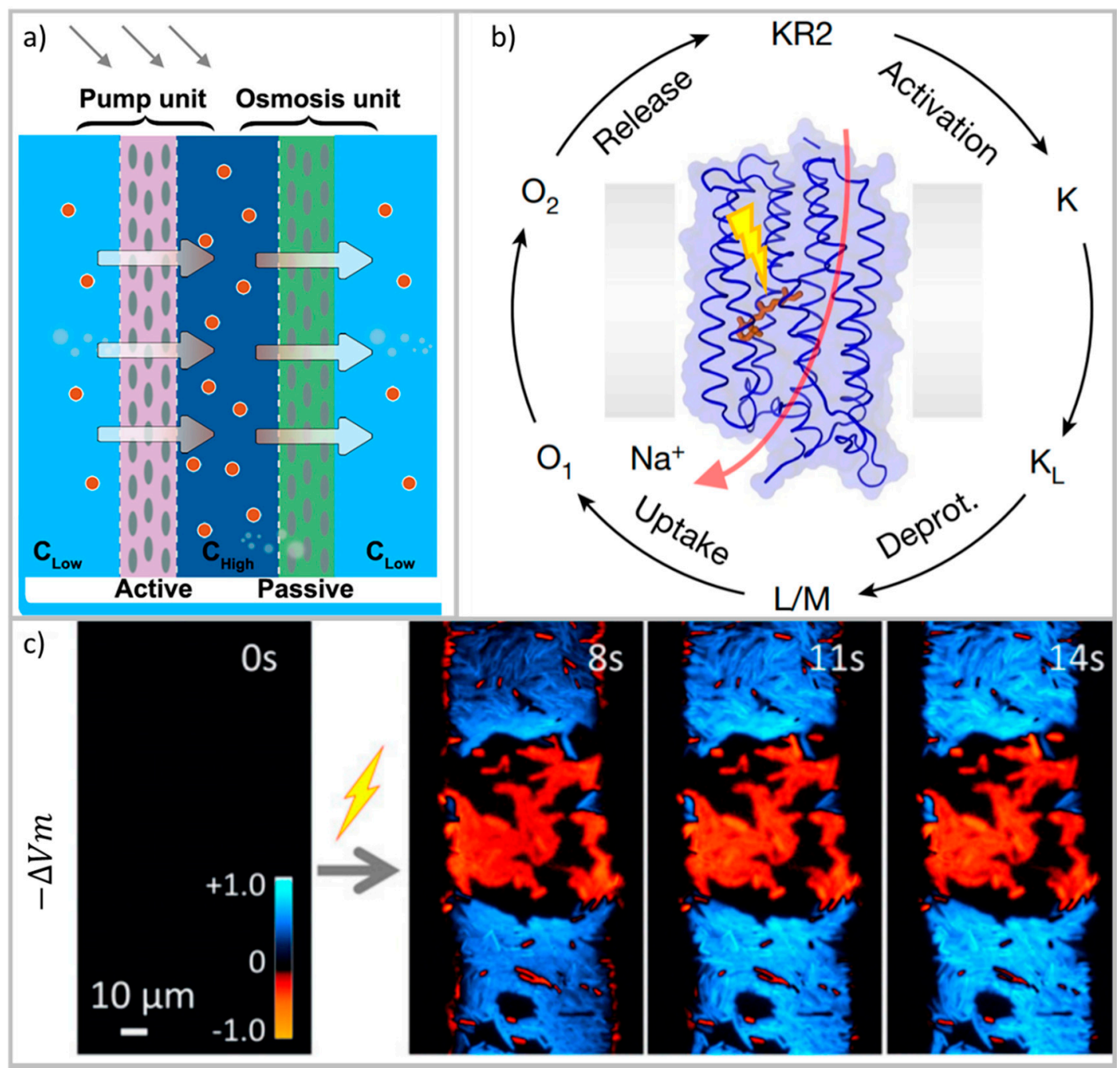

Figure 19. Optically induced membrane potentials causing membrane potential variation. (a) ion transport through bacterial membrane using active and passive optical regimes [2]. (b) Light driven $\mathrm{Na}^{+}$pump [152]. (c) Light induced membrane depolarization (red) due to UV irradiation causing phototoxicity [148]. Reproduced with permission from (a) ref. [2] Copyright (2019), Elsevier; (b) ref. [152] Copyright (2020), Springer Nature; (c) ref. [148] Copyright (2020), National Academy of Science.

Fluorescent markers can be utilized for ion transport in neuron cells, and can also be used to indicate molecular interactions and transport through bacterial membrane [158-160]. With more complicates pathways because of their molecular specificity, the transport of ions or charged molecules relates to mechanisms of ion transport through nanopore (1D diffusion) and on membrane surfaces (2D diffusion) [161]. The transport of charged molecules in respect of ion transport utilizes fluorescent techniques for fundamental investigation [162]. Charged molecules of antimicrobial peptide (AMPs) were reported to have been transported through the bacterial membrane [158].

Evidence of the transport of charged AMP molecules from outside to within the inner membrane is shown in in Figure 20b. Based on results, we can evaluate the rate of AMP deposition and localization from the neutron scattering results and from the fluorescence of localization images, which clearly show the adsorption, aggregation and insertion of AMPs on bacterial membrane [158]. This relates to the translocation of AMPs in the form of $1 \mathrm{D}$ diffusion through membrane pores to aggregate in the bacterial membrane. 


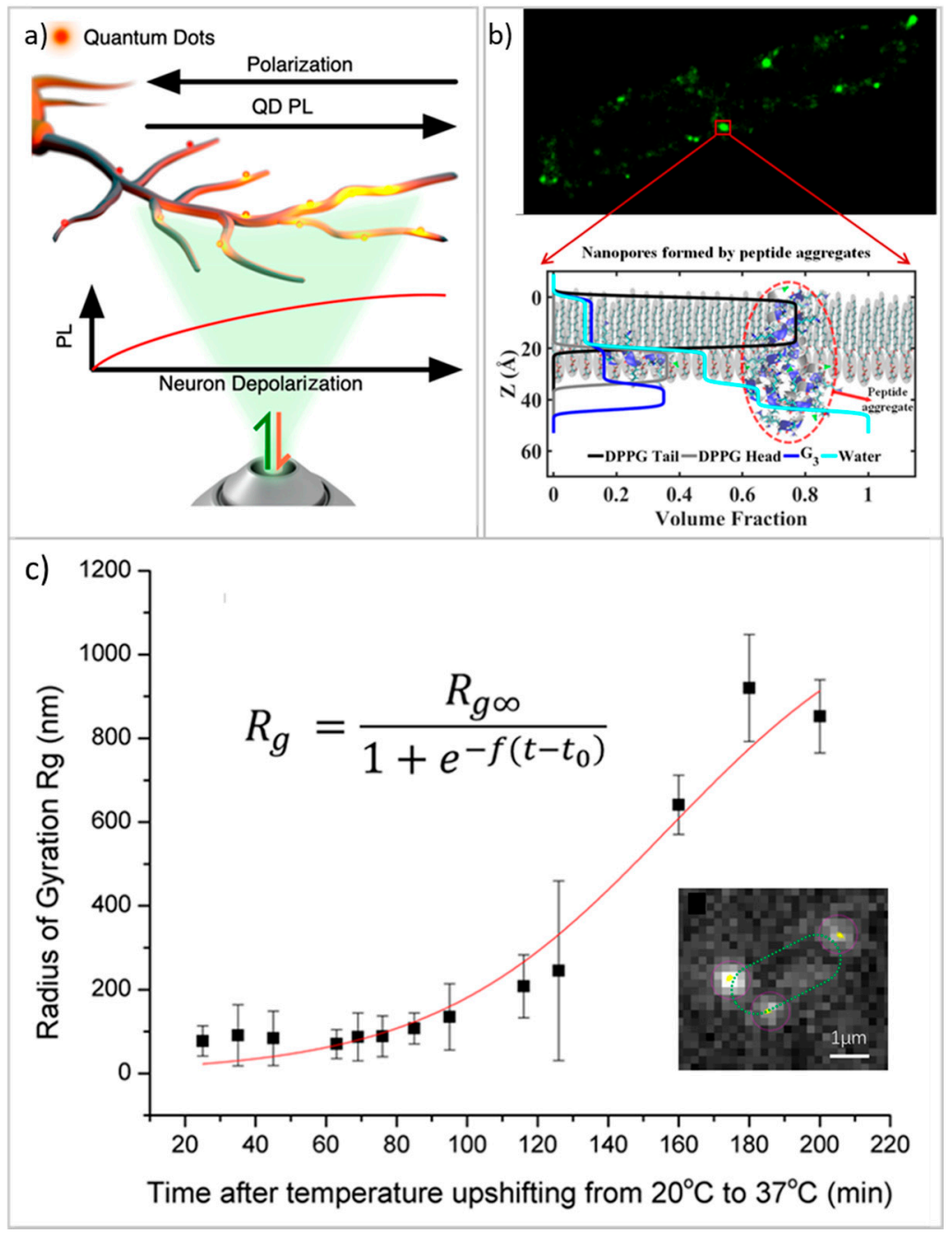

Figure 20. Fluorescent markers indicate ion and molecular transport. (a) using QDs to trace ion transport responses on neurons [157]. (b) decorated anti-microbial peptides indicate localization on bacterial membrane [158]. (c) polyelectrolyte molecules diffused on membrane with a mean square displacement relationship, and transported through bacterial membrane showing the rate of molecular export from inside [156]. Reproduced with permission from (a) ref. [157] Copyright (2019), American Chemical Society; (b) ref. [158] Copyright (2020), American Chemical Society; (c) ref. [156] Copyright (2019), American Chemical Society.

As well as the investigation of charged molecular uptake, fluorescent markers can also be used to indicate the export of charged molecules. Bacteria can combine with charged molecules being exported and imported simultaneously. Tracing the export mechanism of charged polyelectrolyte molecules as $\mathrm{K} 1$ capsular polysialic acid was more challenging. Using immunology and real-time labelling methods, the diffusion of K1 capsular polysaccharides on membranes with sub-diffusion revealed a rafting model for lipid diffusion, shown in Figure 20c. With real time tracing and improvements in contrast [163], the rate of transport and capsular formation were investigated [156]. The mobility of the K1 charged molecules on bacterial membrane was linked to a 2D diffusion in a sub-diffusive regime, while charged molecules in other systems with active transport, such as the mobility of proteins in bacterial cytoplasm in 3D diffusion, can be superdiffusive [162].

From the perspectives of ion transport on and through 2D materials to the transport of charged molecules on and through 2D bacterial membranes, transport in the two different systems share a similar behavior in terms of diffusion. Bacterial mimicking applications can 
utilize the basic knowledge and the complex mechanisms of charged molecule transport in living bacteria for better sustainability and efficiency.

\section{Summary and Outlook}

Ion transport is a principle that underlies a variety of current and future technologies. This review has provided the fundamental knowledge of capacitance and ion sieving and transportation, which provides the basic methods behind electrochemical ion transport phenomena that are used in a variety of applications such as energy storage (focused on microsupercapacitors), molecular transport, ion transport in biological cells and energy harvesting (osmotic power or blue energy). The review described the capacitive properties and charge storage mechanisms from different model systems, and the context was then expanded to include the capacitive properties of two-dimensional materials such as graphene, metal oxide and transition metal dichalcogenide (TMDs). This provided a better understanding of ionic sieving, transport through membranes (both organic and inorganic cells), and the design of nano- to angstrom-scale transport channels. As the concepts of capacitance represent the core features of the development of ion transport mechanisms, a discussion of context was necessary regarding aspects relating to the capacitance of two-dimensional material. Two-dimensional materials display their own unique charge storage mechanisms, even when working the similar materials. Changing the material dimensions - the thickness, lateral size and formation of heterostructural materials - can greatly alter the capacitive properties. In terms of applications, we demonstrate the novel functionalities of microsupercapacitors as well as their capacity for energy storage. These functionalities can be found in stimulus-responsive microsupercapacitors, which offers exciting applications in direct visualization of energy storages, light-induced energy storage and photodetection, and ion transport control. Their performances may be enhanced through the use of plasmonic nanomaterials, the generation of electron-hole pairs in a direct-bandgap 2D semiconductor, and high-aspect-ratio (3D) interdigitated electrodes. Through natural imitation, ion transport in living cells and the effects of photo/thermal induction may offer fascinating applications which can be further linked to more complicated ion transport systems, as well as potential uses in living bacterial systems. The design has the potential to be tunable, selective, efficient, energy free and reproducible at a larger scale.

Author Contributions: N.U., S.P., W.H. and P.I. conceived and designed the review article and wrote the manuscript with contributions from all authors. Specifically, N.U. wrote the section relating to the stimulus-responsive microsupercapacitors and their applications. S.P. wrote the section on optical/thermal induction and ion transport/charged molecule translocation in living cells with P.P. W.H. wrote about the principles of ion transport and intercalation of layered materials with A.B. and P.S. and P.I. wrote the section on the principle of capacitance with K.J. and P.K. All authors have read and agreed to the published version of the manuscript.

Funding: This research was funded by Rajamangala University of Technology Isan; Kasetsart University Research and Development Institute (FF[KU]25.64); Faculty of Science, Kasetsart University (PRF-P6/2563); Kasetsart University Research and Development Institute (KURDI 11.64). The APC was funded by MDPI.

Institutional Review Board Statement: Not applicable.

Informed Consent Statement: Not applicable.

Acknowledgments: N.U. wishes to acknowledge funding from Chulachomklao Royal Military Academy. S.P. wishes to acknowledge funding from Kasetsart University Research and Development Institute (FF[KU]25.64) and the Faculty of Science, Kasetsart University, Thailand (PRF-P6/2563). W.H. wishes to acknowledge funding from Kasetsart University Research and Development Institute (KURDI 11.64) and the Faculty of Science, Kasetsart University, Thailand (PRF-P6/2563). P.I. wishes to acknowledge funding and the provision of facilities from Rajamangala University of Technology Isan and an industrial grant from PTT.PLC. 
Conflicts of Interest: The authors declare no conflict of interest.

\section{References}

1. Hille, B. Ion Channels of Excitable Membranes, 3rd ed.; Sinauer: Sunderland, MA, USA, 2001; Chapter 14.

2. Xiao, K.; Jiang, L.; Antonietti, M. Ion Transport in Nanofluidic Devices for Energy Harvesting. Joule 2019, 3, 2364-2380. [CrossRef]

3. Gotter, A.L.; Kaetzel, M.A.; Dedman, J.R. Electrophorus electricus as a Model System for the Study of Membrane Excitability. Comp. Biochem. Physiol. A Mol. Integr. Physiol. 1998, 119, 225-241. [CrossRef]

4. Hirunpinyopas, W.; Rodgers, A.N.J.; Worrall, S.D.; Bissett, M.A.; Dryfe, R.A.W. Hydrogen Evolution at Liquid I Liquid Interfaces Catalyzed by 2D Materials. Chem. Nano Mat. 2017, 3, 428-435. [CrossRef]

5. Kahan, R.J.; Hirunpinyopas, W.; Cid, J.; Ingleson, M.J.; Dryfe, R.A.W. Well-Defined Boron/Nitrogen-Doped Polycyclic Aromatic Hydrocarbons are Active Electrocatalysts for the Oxygen Reduction Reaction. Chem. Mater. 2019, 31, 1891-1898. [CrossRef]

6. Iamprasertkun, P.; Hirunpinyopas, W.; Deerattrakul, V.; Sawangphruk, M.; Nualchimplee, C. Controlling the Flake Size of Bifunctional 2D WSe 2 Nanosheets as Flexible Binders and Supercapacitor Materials. Nanoscale Adv. 2021, 3, 653-660. [CrossRef]

7. Worrall, S.D.; Bissett, M.A.; Hirunpinyopas, W.; Attfield, M.P.; Dryfe, R.A.W. Facile Fabrication of Metal-Organic Framework HKUST-1-Based Rewritable Data Storage Devices. J. Mater. Chem. C 2016, 4, 8687-8695. [CrossRef]

8. Tibodee, A.; Hirunpinyopas, W.; Jeamjumnunja, K.; Sirisaksoontorn, W. Synthesis of Carbon Dots from the Biomass Products for Supercapacitor Applications. IOP Conf. Ser. Mater. Sci. Eng. 2020, 773, 012022. [CrossRef]

9. Hirunpinyopas, W.; Iamprasertkun, P.; Bissett, M.A.; Dryfe, R.A.W. Tunable Charge/Size Selective Ion Sieving with Ultrahigh Water Permeance through Laminar Graphene Membranes. Carbon 2020, 156, 119-129. [CrossRef]

10. Hirunpinyopas, W.; Prestat, E.; Iamprasertkun, P.; Bissett, M.A.; Dryfe, R.A.W. Potential Dependent Ionic Sieving through Functionalized Laminar $\mathrm{MoS}_{2}$ Membranes. 2D Mater. 2020, 7, 015030. [CrossRef]

11. Hirunpinyopas, W.; Prestat, E.; Worrall, S.D.; Haigh, S.J.; Dryfe, R.A.W.; Bissett, M.A. Desalination and Nanofiltration Through Functionalized Laminar $\mathrm{MoS}_{2}$ Membranes. ACS Nano 2017, 11, 11082-11090. [CrossRef]

12. Senthil Murugan, A.; Kiruthika, M.; Abel Noelson, E.R.; Yogapandi, P.; Gnana kumar, G.; Annaraj, J. Fluorescent Sensor for in-Vivo Bio-Imaging, Precise Tracking of $\mathrm{Fe}^{3+}$ ions in Zebrafish Embryos and Visual Measuring of $\mathrm{Cu}^{2+}$ Ions in Pico-Molar Level. Arabian J. Chem. 2021, 14, 102910. [CrossRef]

13. Novoselov, K.S.; Geim, A.K.; Morozov, S.V.; Jiang, D.; Zhang, Y.; Dubonos, S.V.; Grigorieva, I.V.; Firsov, A.A. Electric Field Effect in Atomically Thin Carbon Films. Science 2004, 306, 666-669. [CrossRef] [PubMed]

14. Novoselov, K.S.; Jiang, D.; Schedin, F.; Booth, T.J.; Khotkevich, V.V.; Morozov, S.V.; Geim, A.K. Two-Dimensional Atomic Crystals. Proc. Natl. Acad. Sci. USA 2005, 102, 10451-10453. [CrossRef] [PubMed]

15. Cassabois, G.; Valvin, P.; Gil, B. Hexagonal Boron Nitride Is An Indirect Bandgap Semiconductor. Nat. Photonics 2016, 10, 262. [CrossRef]

16. Naguib, M.; Mochalin, V.N.; Barsoum, M.W.; Gogotsi, Y. 25th Anniversary Article: MXenes: A New Family of Two-Dimensional Materials. Adv. Mater. 2014, 26, 992-1005. [CrossRef]

17. Iamprasertkun, P.; Hirunpinyopas, W.; Tripathi, A.M.; Bissett, M.A.; Dryfe, R.A.W. Electrochemical Intercalation of $\mathrm{MoO}_{3}-\mathrm{MoS}_{2}$ Composite Electrodes: Charge Storage Mechanism of Non-Hydrated Cations. Electrochim. Acta 2019, 307, 176-187. [CrossRef]

18. Deerattrakul, V.; Hirunpinyopas, W.; Pisitpipathsin, N.; Saisopa, T.; Sawangphruk, M.; Nualchimplee, C.; Iamprasertkun, P. The Electrochemistry of Size Dependent Graphene via Liquid Phase Exfoliation: Capacitance and Ionic Transport. Phys. Chem. Chem. Phys. 2021, 23, 11616-11623. [CrossRef]

19. Dean, C.R.; Young, A.F.; Meric, I.; Lee, C.; Wang, L.; Sorgenfrei, S.; Watanabe, K.; Taniguchi, T.; Kim, P.; Shepard, K.L.; et al. Boron Nitride Substrates for High-Quality Graphene Electronics. Nat. Nanotechnol. 2010, 5, 722-726. [CrossRef]

20. Giovannetti, G.; Khomyakov, P.A.; Brocks, G.; Kelly, P.J.; van den Brink, J. Substrate-Induced Band Gap in Graphene on Hexagonal Boron Nitride: Ab Initio Density Functional Calculations. Phys. Rev. B 2007, 76, 073103. [CrossRef]

21. Mayorov, A.S.; Gorbachev, R.V.; Morozov, S.V.; Britnell, L.; Jalil, R.; Ponomarenko, L.A.; Blake, P.; Novoselov, K.S.; Watanabe, K.; Taniguchi, T.; et al. Micrometer-Scale Ballistic Transport in Encapsulated Graphene at Room Temperature. Nano Lett. 2011, 11, 2396-2399. [CrossRef]

22. Wang, L.; Meric, I.; Huang, P.Y.; Gao, Q.; Gao, Y.; Tran, H.; Taniguchi, T.; Watanabe, K.; Campos, L.M.; Muller, D.A.; et al. One-Dimensional Electrical Contact to a Two-Dimensional Material. Science 2013, 342, 614. [CrossRef] [PubMed]

23. Banszerus, L.; Schmitz, M.; Engels, S.; Dauber, J.; Oellers, M.; Haupt, F.; Watanabe, K.; Taniguchi, T.; Beschoten, B.; Stampfer, C. Ultrahigh-Mobility Graphene Devices from Chemical Vapor Deposition on Reusable Copper. Sci. Adv. 2015, 1, e1500222. [CrossRef]

24. Iamprasertkun, P.; Dryfe, R.A.W. The Capacitance of Graphene: From Model Systems to Large-Scale Devices. In Nanocarbon Electrochemistry; Yang, N., Zhao, G., Foord, J., Eds.; Wiley Online Books; John Wiley \& Sons Ltd.: Chichester, UK, 2020; pp. 33-84.

25. Simon, P.; Gogotsi, Y. Ti ${ }_{3} \mathrm{C}_{2}$ MXenes-Derived $\mathrm{NaTi}_{2}\left(\mathrm{PO}_{4}\right)_{3} / \mathrm{MXene}$ Nanohybrid for Fast and Efficient Hybrievices. Nat. Mater. 2020, 19, 1151-1163. [CrossRef] [PubMed]

26. Zhang, C.; Peng, Z.; Huang, C.; Zhang, B.; Xing, C.; Chen, H.; Cheng, H.; Wang, J.; Tang, S. High-Energy All-In-One Stretchable Micro-Supercapacitor Arrays Based on 3D Laser-Induced Graphene Foams Decorated with Mesoporous ZnP Nanosheets for Self-Powered Stretchable Systems. Nano Energy 2021, 81, 105609. [CrossRef] 
27. Chen, Z.; Xu, X.; Ding, Z.; Wang, K.; Sun, X.; Lu, T.; Konarova, M.; Eguchi, M.; Shapter, J.G.; Pan, L.; et al. Ti ${ }_{3} \mathrm{C}_{2}$ MXenes-Derived $\mathrm{NaTi}_{2}\left(\mathrm{PO}_{4}\right)_{3} / \mathrm{MXene}$ Nanohybrid for Fast and Efficient Hybrid Capacitive Deionization Performance. Chem. Eng. J. 2021, 407, 127148. [CrossRef]

28. Ghanbari, H.; Esfandiar, A. Ion Transport through Graphene Oxide Fibers as Promising Candidate for Blue Energy Harvesting. Carbon 2020, 165, 267-274. [CrossRef]

29. Gong, D.; Yin, Y.; Chen, H.; Guo, B.; Wu, P.; Wang, Y.; Yang, Y.; Li, Z.; He, Y.; Zeng, G. Interfacial Ions Sieving for Ultrafast and Complete Desalination through 2D Nanochannel Defined Graphene Composite Membranes. ACS Nano 2021, 15, 9871-9881. [CrossRef]

30. Pakulski, D.; Czepa, W.; Buffa, S.D.; Ciesielski, A.; Samorì, P. Atom-Thick Membranes for Water Purification and Blue Energy Harvesting. Adv. Funct. Mater. 2020, 30, 1902394. [CrossRef]

31. Lochmann, S.; Bräuniger, Y.; Gottsmann, V.; Galle, L.; Grothe, J.; Kaskel, S. Switchable Supercapacitors with Transistor-Like Gating Characteristics (G-Cap). Adv. Funct. Mater. 2020, 30, 1910439. [CrossRef]

32. Yang, J.; Hu, X.; Kong, X.; Jia, P.; Ji, D.; Quan, D.; Wang, L.; Wen, Q.; Lu, D.; Wu, J.; et al. Photo-Induced Ultrafast Active Ion Transport Through Graphene Oxide Membranes. Nat. Commun. 2019, 10, 1171. [CrossRef]

33. Hong, S.; Zou, G.; Kim, H.; Huang, D.; Wang, P.; Alshareef, H.N. Photothermoelectric Response of $\mathrm{Ti}_{3} \mathrm{C}_{2} \mathrm{~T}_{\mathrm{x}} \mathrm{MXene} \mathrm{Confined} \mathrm{Ion}$ Channels. ACS Nano 2020, 14, 9042-9049. [CrossRef] [PubMed]

34. Béguin, F.; Presser, V.; Balducci, A.; Frackowiak, E. Carbons and Electrolytes for Advanced Supercapacitors. Adv. Mater. 2014, 26, 2219-2251. [CrossRef] [PubMed]

35. Ji, H.; Zhao, X.; Qiao, Z.; Jung, J.; Zhu, Y.; Lu, Y.; Zhang, L.L.; MacDonald, A.H.; Ruoff, R.S. Capacitance of Carbon-Based Electrical Double-Layer Capacitors. Nat. Commun. 2014, 5, 3317. [CrossRef] [PubMed]

36. Fumagalli, L.; Esfandiar, A.; Fabregas, R.; Hu, S.; Ares, P.; Janardanan, A.; Yang, Q.; Radha, B.; Taniguchi, T.; Watanabe, K.; et al. Anomalously Low Dielectric Constant of Confined Water. Science 2018, 360, 1339. [CrossRef] [PubMed]

37. Garlyyev, B.; Xue, S.; Watzele, S.; Scieszka, D.; Bandarenka, A.S. Influence of the Nature of the Alkali Metal Cations on the Electrical Double-Layer Capacitance of Model Pt(111) and Au(111) Electrodes. J. Phys. Chem. Lett. 2018, 9, 1927-1930. [CrossRef] [PubMed]

38. Randin, J.-P.; Yeager, E. Differential Capacitance Study on the Basal Plane of Stress-Annealed Pyrolytic Graphite. J. Electroanal. Chem. Interfacial Electrochem. 1972, 36, 257-276. [CrossRef]

39. Iamprasertkun, P.; Ejigu, A.; Dryfe, R.A.W. Understanding the Electrochemistry of “Water-in-Salt” Electrolytes: Basal Plane Highly Ordered Pyrolytic Graphite as a Model System. Chem. Sci. 2020, 11, 6978-6989. [CrossRef]

40. Xia, J.; Chen, F.; Li, J.; Tao, N. Measurement of the Quantum Capacitance of Graphene. Nat. Nanotechnol. 2009, 4, 505-509. [CrossRef]

41. Geim, A.K.; Novoselov, K.S. The Rise of Graphene. Nat. Mater. 2007, 6, 183-191. [CrossRef]

42. Yuan, W.; Zhou, Y.; Li, Y.; Li, C.; Peng, H.; Zhang, J.; Liu, Z.; Dai, L.; Shi, G. The Edge- and Basal-Plane-Specific Electrochemistry of a Single-Layer Graphene Sheet. Sci. Rep. 2013, 3, 2248. [CrossRef]

43. Iamprasertkun, P.; Hirunpinyopas, W.; Keerthi, A.; Wang, B.; Radha, B.; Bissett, M.A.; Dryfe, R.A.W. Capacitance of Basal Plane and Edge-Oriented Highly Ordered Pyrolytic Graphite: Specific Ion Effects. J. Phys. Chem. Lett. 2019, 10, 617-623. [CrossRef]

44. Stoller, M.D.; Park, S.; Zhu, Y.; An, J.; Ruoff, R.S. Graphene-Based Ultracapacitors. Nano Lett. 2008, 8, 3498-3502. [CrossRef] [PubMed]

45. Fischer, J.E.; Thompson, T.E. Graphite Intercalation Compounds. Phys. Today 1978, 31, 36-45. [CrossRef]

46. Setton, R. The Graphite Intercalation Compounds: Their Uses in Industry and Chemistry. Synth. Met. 1988, $23,467-473$. [CrossRef]

47. Joensen, P.; Frindt, R.F.; Morrison, S.R. Single-Layer MoS 2. Mater. Res. Bull. 1986, 21, 457-461. [CrossRef]

48. Divigalpitiya, W.M.R.; Frindt, R.F.; Morrison, S.R. Inclusion Systems of Organic Molecules in Restacked Single-Layer Molybdenum Disulfide. Science 1989, 246, 369-371. [CrossRef]

49. Gogotsi, Y.; Penner, R.M. Energy Storage in Nanomaterials-Capacitive, Pseudocapacitive, or Battery-like? ACS Nano 2018, 12, 2081-2083. [CrossRef]

50. Zeng, Z.; Yin, Z.; Huang, X.; Li, H.; He, Q.; Lu, G.; Boey, F.; Zhang, H. Single-Layer Semiconducting Nanosheets: High-Yield Preparation and Device Fabrication. Angew. Chem. Int. Ed. 2011, 50, 11093-11097. [CrossRef]

51. Hitz, E.; Wan, J.; Patel, A.; Xu, Y.; Meshi, L.; Dai, J.; Chen, Y.; Lu, A.; Davydov, A.V.; Hu, L. Electrochemical Intercalation of Lithium Ions into $\mathrm{NbSe}_{2}$ Nanosheets. ACS Appl. Mater. Interfaces 2016, 8, 11390-11395. [CrossRef]

52. Bard, A.J.; Faulkner, L.R. Electrochemical Methods Fundamentals and Applications, 2nd ed.; Wiley: Hoboken, NJ, USA, 2001.

53. Wang, J. Analytical Electrochemistry, 2nd ed.; Wiley: Weinheim, Germany, 2000.

54. Pletcher, D. A First Course in Electrode Processes, 2nd ed.; RSC Publishing: London, UK, 2009.

55. Sparreboom, W.; van den Berg, A.; Eijkel, J.C.T. Principles and Applications of Nanofluidic Transport. Nat. Nanotechnol. 2009, 4, 713-720. [CrossRef]

56. Hong, S.; Constans, C.; Surmani Martins, M.V.; Seow, Y.C.; Guevara Carrió, J.A.; Garaj, S. Scalable Graphene-Based Membranes for Ionic Sieving with Ultrahigh Charge Selectivity. Nano Lett. 2017, 17, 728-732. [CrossRef]

57. Feng, J.; Graf, M.; Liu, K.; Ovchinnikov, D.; Dumcenco, D.; Heiranian, M.; Nandigana, V.; Aluru, N.R.; Kis, A.; Radenovic, A. Single-Layer $\mathrm{MoS}_{2}$ Nanopores as Nanopower Generators. Nature 2016, 536, 197-200. [CrossRef] [PubMed] 
58. Abraham, J.; Vasu, K.S.; Williams, C.D.; Gopinadhan, K.; Su, Y.; Cherian, C.T.; Dix, J.; Prestat, E.; Haigh, S.J.; Grigorieva, I.V.; et al. Tunable Sieving of Ions Using Graphene Oxide Membranes. Nat. Nanotechnol. 2017, 12, 546-550. [CrossRef] [PubMed]

59. Duan, C.; Majumdar, A. Anomalous Ion Transport in 2-nm Hydrophilic Nanochannels. Nat. Nanotechnol. $2010,5,848-852$. [CrossRef]

60. Karnik, R.; Duan, C.; Castelino, K.; Daiguji, H.; Majumdar, A. Rectification of Ionic Current in a Nanofluidic Diode. Nano Lett. 2007, 7, 547-551. [CrossRef] [PubMed]

61. Duan, C.; Wang, W.; Xie, Q. Review Article: Fabrication of Nanofluidic Devices. Biomicrofluidics 2013, 7, 026501. [CrossRef]

62. Schoch, R.B.; Lintel, H.V.; Renaud, P. Effect of the Surface Charge on Ion Transport Through Nanoslits. Phys. Fluids 2005, 17, 100604. [CrossRef]

63. Schoch, R.B.; Renaud, P. Ion Transport Through Nanoslits Dominated by the Effective Surface Charge. Appl. Phys. Lett. 2005, 86, 253111. [CrossRef]

64. Stein, D.; Kruithof, M.; Dekker, C. Surface-Charge-Governed Ion Transport in Nanofluidic Channels. Phys. Rev. Lett. 2004, 93, 035901. [CrossRef]

65. Daiguji, H.; Yang, P.; Majumdar, A. Ion Transport in Nanofluidic Channels. Nano Lett. 2004, 4, 137-142. [CrossRef]

66. Jung, W.; Kim, J.; Kim, S.; Park, H.G.; Jung, Y.; Han, C.-S. A Novel Fabrication of 3.6 nm High Graphene Nanochannels for Ultrafast Ion Transport. Adv. Mater. 2017, 29, 1605854. [CrossRef]

67. Algara-Siller, G.; Lehtinen, O.; Wang, F.C.; Nair, R.R.; Kaiser, U.; Wu, H.A.; Geim, A.K.; Grigorieva, I.V. Square Ice in Graphene Nanocapillaries. Nature 2015, 519, 443-445. [CrossRef]

68. Radha, B.; Esfandiar, A.; Wang, F.C.; Rooney, A.P.; Gopinadhan, K.; Keerthi, A.; Mishchenko, A.; Janardanan, A.; Blake, P.; Fumagalli, L.; et al. Molecular Transport Through Capillaries Made with Atomic-Scale Precision. Nature 2016, 538, $222-225$. [CrossRef] [PubMed]

69. Esfandiar, A.; Radha, B.; Wang, F.C.; Yang, Q.; Hu, S.; Garaj, S.; Nair, R.R.; Geim, A.K.; Gopinadhan, K. Size Effect in Ion Transport Through Angstrom-Scale Slits. Science 2017, 358, 511-513. [CrossRef] [PubMed]

70. Zangi, R.; Engberts, J.B.F.N. Physisorption of Hydroxide Ions from Aqueous Solution to a Hydrophobic Surface. J. Am. Chem. Soc. 2005, 127, 2272-2276. [CrossRef]

71. Scheu, R.; Rankin, B.M.; Chen, Y.; Jena, K.C.; Ben-Amotz, D.; Roke, S. Charge Asymmetry at Aqueous Hydrophobic Interfaces and Hydration Shells. Angew. Chem. Int. Ed. 2014, 53, 9560-9563. [CrossRef] [PubMed]

72. Baker, R.A. Membrane Technology and Applications, 3rd ed.; John Wiley \& Sons, Ltd.: Chichester, UK, $2004 ;$ p. 575.

73. Lee, A.; Elam, J.W.; Darling, S.B. Membrane Materials for Water Purification: Design, Development, and Application. Environ. Sci. Water Res. Technol. 2016, 2, 17-42. [CrossRef]

74. Ochoa, N.A.; Masuelli, M.; Marchese, J. Development of Charged Ion Exchange Resin-Polymer Ultrafiltration Membranes to Reduce Organic Fouling. J. Membr. Sci. 2006, 278, 457-463. [CrossRef]

75. Tang, Y.; Xue, Z.; Zhou, X.; Xie, X.; Tang, C.-Y. Novel Sulfonated Polysulfone Ion Exchange Membranes for Ionic Polymer-Metal Composite Actuators. Sens. Actuators B 2014, 202, 1164-1174. [CrossRef]

76. Kim, A.R.; Vinothkannan, M.; Song, M.H.; Lee, J.-Y.; Lee, H.-K.; Yoo, D.J. Amine Functionalized Carbon Nanotube (ACNT) Filled in Sulfonated Poly(Ether Ether Ketone) Membrane: Effects of ACNT in Improving Polymer Electrolyte Fuel Cell Performance Under Reduced Relative Humidity. Compos. Part B 2020, 188, 107890. [CrossRef]

77. Vilela, S.M.F.; Navarro, J.A.R.; Barbosa, P.; Mendes, R.F.; Pérez-Sánchez, G.; Nowell, H.; Ananias, D.; Figueiredo, F.; Gomes, J.R.B.; Tomé, J.P.C.; et al. Multifunctionality in an Ion-Exchanged Porous Metal-Organic Framework. J. Am. Chem. Soc. 2021, 143, 1365-1376. [CrossRef] [PubMed]

78. Kumar, P.; Pournara, A.; Kim, K.-H.; Bansal, V.; Rapti, S.; Manos, M.J. Metal-Organic Frameworks: Challenges and Opportunities for Ion-Exchange/Sorption Applications. Prog. Mater. Sci. 2017, 86, 25-74. [CrossRef]

79. Kim, A.R.; Vinothkannan, M.; Yoo, D.J. Artificially Designed, Low Humidifying Organic-Inorganic $\left(\mathrm{SFBC}^{-50 / F S i O}\right)_{2}$ Composite Membrane for Electrolyte Applications of Fuel Cells. Compos. Part B 2017, 130, 103-118. [CrossRef]

80. O'Hern, S.C.; Stewart, C.A.; Boutilier, M.S.H.; Idrobo, J.-C.; Bhaviripudi, S.; Das, S.K.; Kong, J.; Laoui, T.; Atieh, M.; Karnik, R. Selective Molecular Transport through Intrinsic Defects in a Single Layer of CVD Graphene. ACS Nano 2012, 6, 10130-10138. [CrossRef] [PubMed]

81. O'Hern, S.C.; Boutilier, M.S.H.; Idrobo, J.-C.; Song, Y.; Kong, J.; Laoui, T.; Atieh, M.; Karnik, R. Selective Ionic Transport Through Tunable Subnanometer Pores in Single-Layer Graphene Membranes. Nano Lett. 2014, 14, 1234-1241. [CrossRef] [PubMed]

82. Celebi, K.; Buchheim, J.; Wyss, R.M.; Droudian, A.; Gasser, P.; Shorubalko, I.; Kye, J.-I.; Lee, C.; Park, H.G. Ultimate Permeation Across Atomically Thin Porous Graphene. Science 2014, 344, 289-292. [CrossRef]

83. Surwade, S.P.; Smirnov, S.N.; Vlassiouk, I.V.; Unocic, R.R.; Veith, G.M.; Dai, S.; Mahurin, S.M. Water Desalination Using Nanoporous Single-Layer Graphene. Nat. Nanotechnol. 2015, 10, 459-464. [CrossRef]

84. Cohen-Tanugi, D.; Grossman, J.C. Water Desalination across Nanoporous Graphene. Nano Lett. 2012, 12, 3602-3608. [CrossRef]

85. Dikin, D.A.; Stankovich, S.; Zimney, E.J.; Piner, R.D.; Dommett, G.H.B.; Evmenenko, G.; Nguyen, S.T.; Ruoff, R.S. Preparation and Characterization of Graphene Oxide Paper. Nature 2007, 448, 457. [CrossRef]

86. Yeh, C.-N.; Raidongia, K.; Shao, J.; Yang, Q.-H.; Huang, J. On the Origin of the Stability of Graphene Oxide Membranes in Water. Nat. Chem. 2015, 7, 166-170. [CrossRef] 
87. Chen, L.; Shi, G.; Shen, J.; Peng, B.; Zhang, B.; Wang, Y.; Bian, F.; Wang, J.; Li, D.; Qian, Z.; et al. Ion Sieving in Graphene Oxide Membranes via Cationic Control of Interlayer Spacing. Nature 2017, 550, 380-383. [CrossRef]

88. Huang, L.; Zhang, M.; Li, C.; Shi, G. Graphene-Based Membranes for Molecular Separation. J. Phys. Chem. Lett. 2015, 6, 2806-2815. [CrossRef] [PubMed]

89. Yang, Q.; Su, Y.; Chi, C.; Cherian, C.T.; Huang, K.; Kravets, V.G.; Wang, F.C.; Zhang, J.C.; Pratt, A.; Grigorenko, A.N.; et al. Ultrathin Graphene-Based Membrane with Precise Molecular Sieving and Ultrafast Solvent Permeation. Nat. Mater. 2017, 16, 1198-1202. [CrossRef] [PubMed]

90. Zheng, S.; Tu, Q.; Urban, J.J.; Li, S.; Mi, B. Swelling of Graphene Oxide Membranes in Aqueous Solution: Characterization of Interlayer Spacing and Insight into Water Transport Mechanisms. ACS Nano 2017, 11, 6440-6450. [CrossRef]

91. Anand, A.; Unnikrishnan, B.; Mao, J.-Y.; Lin, H.-J.; Huang, C.-C. Graphene-Based Nanofiltration Membranes for Improving Salt Rejection, Water Flux and Antifouling-A review. Desalination 2018, 429, 119-133. [CrossRef]

92. Wei, N.; Peng, X.; Xu, Z. Understanding Water Permeation in Graphene Oxide Membranes. ACS Appl. Mater. Interfaces 2014, 6, 5877-5883. [CrossRef]

93. Nair, R.R.; Wu, H.A.; Jayaram, P.N.; Grigorieva, I.V.; Geim, A.K. Unimpeded Permeation of Water Through Helium-Leak-Tight Graphene-Based Membranes. Science 2012, 335, 442-444. [CrossRef]

94. Mi, B. Graphene Oxide Membranes for Ionic and Molecular Sieving. Science 2014, 343, 740-742. [CrossRef]

95. Joshi, R.K.; Carbone, P.; Wang, F.C.; Kravets, V.G.; Su, Y.; Grigorieva, I.V.; Wu, H.A.; Geim, A.K.; Nair, R.R. Precise and Ultrafast Molecular Sieving Through Graphene Oxide Membranes. Science 2014, 343, 752-754. [CrossRef]

96. Wang, Z.; Tu, Q.; Zheng, S.; Urban, J.J.; Li, S.; Mi, B. Understanding the Aqueous Stability and Filtration Capability of MoS 2 Membranes. Nano Lett. 2017, 17, 7289-7298. [CrossRef]

97. Rollings, R.C.; Kuan, A.T.; Golovchenko, J.A. Ion Selectivity of Graphene Nanopores. Nat. Commun. 2016, 7, 11408. [CrossRef]

98. Malmivuo, J.; Plonsey, R. Subthreshold Membrane Phenomena. In Bioelectromagnetism: Principles and Applications of Bioelectric and Biomagnetic Fields; Oxford University Press: Oxford, UK, 1995; pp. 78-110.

99. Goldman, D.E. Potential, Impedance, and Rectification in Membranes. J. Gen. Physiol. 1943, 27, 37-60. [CrossRef]

100. Hodgkin, A.L.; Katz, B. The Effect of Sodium Ions on the Electrical Activity of the Giant Axon of the Squid. J. Physiol. 1949, 108, 37-77. [CrossRef]

101. Sandblom, J.P.; Eisenman, G. Membrane Potentials at Zero Current: The Significance of a Constant Ionic Permeability Ratio. Biophys. J. 1967, 7, 217-242. [CrossRef]

102. MacGillivray, A.D.; Hare, D. Applicability of Goldman's Constant Field Assumption to Biological Systems. J. Theor. Biol. 1969, 25, 113-126. [CrossRef]

103. Fernández, M.M.; Flores, O.O.; Iglesias, G.R.; Castellanos, G.R.; Delgado, A.V.; Martinez, L.A. Ion Transport through Graphene Oxide Fibers. J. Renew. Sustain. Energy 2017, 9, 014101. [CrossRef]

104. Siria, A.; Bocquet, M.-L.; Bocquet, L. New Avenues for the Large-Scale Harvesting of Blue Energy. Nat. Rev. Chem. 2017, 1, 0091. [CrossRef]

105. Siria, A.; Poncharal, P.; Biance, A.-L.; Fulcrand, R.; Blase, X.; Purcell, S.T.; Bocquet, L. Giant Osmotic Energy Conversion Measured in a Single Transmembrane Boron Nitride Nanotube. Nature 2013, 494, 455-458. [CrossRef] [PubMed]

106. Aliprandi, A.; Pakulski, D.; Ciesielski, A.; Samorì, P. Punctured Two-Dimensional Sheets for Harvesting Blue Energy. ACS Nano 2017, 11, 10654-10658. [CrossRef]

107. Graf, M.; Lihter, M.; Unuchek, D.; Sarathy, A.; Leburton, J.-P.; Kis, A.; Radenovic, A. Light-Enhanced Blue Energy Generation Using $\mathrm{MoS}_{2}$ Nanopores. Joule 2019, 3, 1549-1564. [CrossRef]

108. Liu, G.; Chen, T.; Xu, J.; Wang, K. Blue Energy Harvesting on Nanostructured Carbon Materials. J. Mater. Chem. A 2018, 6 , 18357-18377. [CrossRef]

109. Kyeremateng, N.A.; Brousse, T.; Pech, D. Microsupercapacitors as Miniaturized Energy-Storage Components for On-Chip Electronics. Nat. Nanotechnol. 2017, 12, 7-15. [CrossRef]

110. Wang, Z.L. Self-Powered Nanosensors and Nanosystems. Adv. Mater. 2012, 24, 280-285. [CrossRef]

111. Ferris, A.; Bourrier, D.; Garbarino, S.; Guay, D.; Pech, D. 3D Interdigitated Microsupercapacitors with Record Areal Cell Capacitance. Small 2019, 15, 1901224. [CrossRef] [PubMed]

112. Shen, C.; Xu, S.; Xie, Y.; Sanghadasa, M.; Wang, X.; Lin, L. A Review of On-Chip Micro Supercapacitors for Integrated SelfPowering Systems. J. Microelectromech. Syst. 2017, 26, 949-965. [CrossRef]

113. Pech, D.; Brunet, M.; Dinh, T.M.; Armstrong, K.; Gaudet, J.; Guay, D. Influence of the Configuration in Planar Interdigitated Electrochemical Micro-Capacitors. J. Power Sources 2013, 230, 230-235. [CrossRef]

114. Pech, D.; Brunet, M.; Durou, H.; Huang, P.; Mochalin, V.; Gogotsi, Y.; Taberna, P.-L.; Simon, P. Ultrahigh-Power Micrometre-Sized Supercapacitors Based on Onion-like Carbon. Nat. Nanotechnol. 2010, 5, 651-654. [CrossRef] [PubMed]

115. Shen, C.; Wang, X.; Zhang, W.; Kang, F. A High-Performance Three-Dimensional Micro Supercapacitor Based on Self-Supporting Composite Materials. J. Power Sources 2011, 196, 10465-10471. [CrossRef]

116. El-Kady, M.F.; Kaner, R.B. Scalable Fabrication of High-Power Graphene Micro-Supercapacitors for Flexible and On-Chip Energy Storage. Nat. Commun. 2013, 4, 1475. [CrossRef]

117. Shen, C.; Wang, X.; Zhang, W.; Kang, F. Direct Prototyping of Patterned Nanoporous Carbon: A Route from Materials to On-chip Devices. Sci. Rep. 2013, 3, 2294. [CrossRef] 
118. Pu, J.; Wang, X.; Zhang, T.; Li, S.; Liu, J.; Komvopoulos, K. High-Energy-Density, All-Solid-State Microsupercapacitors with Three-Dimensional Interdigital Electrodes of Carbon/Polymer Electrolyte Composite. Nanotechnology 2015, 27, 045701. [CrossRef]

119. Zhang, P.; Zhu, F.; Wang, F.; Wang, J.; Dong, R.; Zhuang, X.; Schmidt, O.G.; Feng, X. Stimulus-Responsive Micro-Supercapacitors with Ultrahigh Energy Density and Reversible Electrochromic Window. Adv. Mater. 2017, 29, 1604491. [CrossRef]

120. Liu, Z.; Wang, H.I.; Narita, A.; Chen, Q.; Mics, Z.; Turchinovich, D.; Kläui, M.; Bonn, M.; Müllen, K. Photoswitchable MicroSupercapacitor Based on a Diarylethene-Graphene Composite Film. J. Am. Chem. Soc. 2017, 139, 9443-9446. [CrossRef]

121. Li, Y.; van de Groep, J.; Talin, A.A.; Brongersma, M.L. Dynamic Tuning of Gap Plasmon Resonances Using a Solid-State Electrochromic Device. Nano Lett. 2019, 19, 7988-7995. [CrossRef] [PubMed]

122. Hopmann, E.; Elezzabi, A.Y. Plasmochromic Nanocavity Dynamic Light Color Switching. Nano Lett. 2020, 20, 1876-1882. [CrossRef]

123. Link, S.; El-Sayed, M.A. Spectral Properties and Relaxation Dynamics of Surface Plasmon Electronic Oscillations in Gold and Silver Nanodots and Nanorods. J. Phys. Chem. B 1999, 103, 8410-8426. [CrossRef]

124. Mock, J.J.; Smith, D.R.; Schultz, S. Local Refractive Index Dependence of Plasmon Resonance Spectra from Individual Nanoparticles. Nano Lett. 2003, 3, 485-491. [CrossRef]

125. Arya, N.; Avasthi, P.; Balakrishnan, V. A Light-Fostered Supercapacitor Performance of Multi-Layered ReS 2 Grown on Conducting Substrates. Nanoscale Adv. 2021, 3, 2089-2102. [CrossRef]

126. Sze, S.M.; Ng, K.K. Photodetectors and Solar Cells. In Physics of Semiconductor Devices; John Wiley \& Sons, Inc.: Hoboken, NJ, USA, 2006; pp. 663-742.

127. Unsuree, N.; Selvi, H.; Crabb, M.G.; Alanis, J.A.; Parkinson, P.; Echtermeyer, T.J. Visible and Infrared Photocurrent Enhancement in a Graphene-Silicon Schottky Photodetector through Surface-States and Electric Field Engineering. 2D Mater. 2019, 6, 041004. [CrossRef]

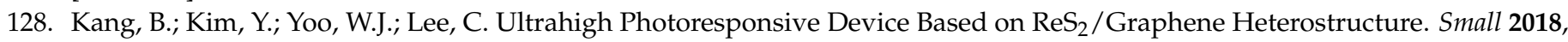
14, 1802593. [CrossRef]

129. Yang, J.; Liu, P.; Li, L.; Tang, Z. Light-Driven Active Ion Transport. Chem. Eur. J. 2020, 26, 13748-13753. [CrossRef]

130. Rajapakse, M.; Karki, B.; Abu, U.O.; Pishgar, S.; Musa, M.R.K.; Riyadh, S.M.S.; Yu, M.; Sumanasekera, G.; Jasinski, J.B. Intercalation as a Versatile Tool for Fabrication, Property Tuning, and Phase Transitions in 2D Materials. NPJ 2D Mater. Appl. 2021, 5, 30. [CrossRef]

131. Zhang, Z.; Kong, X.-Y.; Xie, G.; Li, P.; Xiao, K.; Wen, L.; Jiang, L. “Uphill” Cation Transport: A Bioinspired Photo-Driven Ion Pump. Sci. Adv. 2016, 2, e1600689. [CrossRef] [PubMed]

132. Liu, C.-H.; Chang, Y.-C.; Lee, S.; Zhang, Y.; Zhang, Y.; Norris, T.B.; Zhong, Z. Ultrafast Lateral Photo-Dember Effect in Graphene Induced by Nonequilibrium Hot Carrier Dynamics. Nano Lett. 2015, 15, 4234-4239. [CrossRef] [PubMed]

133. Bakker, M.G.; Frazier, R.M.; Burkett, S.; Bara, J.E.; Chopra, N.; Spear, S.; Pan, S.; Xu, C. Perspectives on Supercapacitors, Pseudocapacitors and Batteries. Nanomater. Energy 2012, 1, 136-158. [CrossRef]

134. Gervilla, V.; Zarshenas, M.; Sangiovanni, D.G.; Sarakinos, K. Anomalous versus Normal Room-Temperature Diffusion of Metal Adatoms on Graphene. J. Phys. Chem. Lett. 2020, 11, 8930-8936. [CrossRef]

135. Akinwande, D.; Brennan, C.J.; Bunch, J.S.; Egberts, P.; Felts, J.R.; Gao, H.; Huang, R.; Kim, J.-S.; Li, T.; Li, Y.; et al. A Review on Mechanics and Mechanical Properties of 2D Materials-Graphene and Beyond. Extreme Mech. Lett. 2017, 13, 42-77. [CrossRef]

136. Stark, M.S.; Kuntz, K.L.; Martens, S.J.; Warren, S.C. Intercalation of Layered Materials from Bulk to 2D. Adv. Mater. 2019, 31, 1808213. [CrossRef]

137. Lo, C.-L.; Catalano, M.; Smithe, K.K.H.; Wang, L.; Zhang, S.; Pop, E.; Kim, M.J.; Chen, Z. Studies of Two-Dimensional h-BN and $\mathrm{MoS}_{2}$ for Potential Diffusion Barrier Application in Copper Interconnect Technology. npj 2D Mater. Appl. 2017, 1, 42. [CrossRef]

138. Massaro, A.; Pecoraro, A.; Muñoz-García, A.B.; Pavone, M. First-Principles Study of Na Intercalation and Diffusion Mechanisms at $2 \mathrm{D} \mathrm{MoS}_{2} /$ Graphene Interfaces. J. Phys. Chem. C 2021, 125, 2276-2286. [CrossRef]

139. Kühne, M.; Zhao, D.; Zschieschang, U.; Buck, R.; Müller, M.; Klauk, H.; Smet, J.H. Wettability Engineering for Studying Ion Transport in 2D Layered Materials. Adv. Mater. Interfaces 2021, 8, 2001453. [CrossRef]

140. Tian, R.; Breshears, M.; Horvath, D.V.; Coleman, J.N. The Rate Performance of Two-Dimensional Material-Based Battery Electrodes May Not Be as Good as Commonly Believed. ACS Nano 2020, 14, 3129-3140. [CrossRef] [PubMed]

141. Tzul, F.O.; Schweiker, K.L.; Makhatadze, G.I. Modulation of Folding Energy Landscape by Charge-Charge Interactions: Linking Experiments with Computational Modeling. Proc. Natl. Acad. Sci. USA 2015, 112, E259. [CrossRef] [PubMed]

142. Zhang, Q.; Zhang, J.; Wan, S.; Wang, W.; Fu, L. Stimuli-Responsive 2D Materials Beyond Graphene. Adv. Funct. Mater. 2018, 28, 1802500. [CrossRef]

143. Ma, Q.; Ren, G.; Xu, K.; Ou, J.Z. Tunable Optical Properties of 2D Materials and Their Applications. Adv. Opt. Mater. 2021, 9 , 2001313. [CrossRef]

144. Xia, F.; Wang, H.; Xiao, D.; Dubey, M.; Ramasubramaniam, A. Two-Dimensional Material Nanophotonics. Nat. Photonics 2014, 8 , 899-907. [CrossRef]

145. Gogotsi, Y.; Anasori, B. The Rise of MXenes. ACS Nano 2019, 13, 8491-8494. [CrossRef]

146. Fazelkhah, A.; Braasch, K.; Afshar, S.; Salimi, E.; Butler, M.; Bridges, G.; Thomson, D. Quantitative Model for Ion Transport and Cytoplasm Conductivity of Chinese Hamster Ovary Cells. Sci. Rep. 2018, 8, 17818. [CrossRef] 
147. Benarroch, J.M.; Asally, M. The Microbiologist's Guide to Membrane Potential Dynamics. Trends Microbiol. 2020, 28 , 304-314. [CrossRef]

148. Stratford, J.P.; Edwards, C.L.A.; Ghanshyam, M.J.; Malyshev, D.; Delise, M.A.; Hayashi, Y.; Asally, M. Electrically Induced Bacterial Membrane-Potential Dynamics Correspond to Cellular Proliferation Capacity. Proc. Natl. Acad. Sci. USA 2019, $116,9552$. [CrossRef]

149. Clausen, M.V.; Hilbers, F.; Poulsen, H. The Structure and Function of the Na,K-ATPase Isoforms in Health and Disease. Front. Physiol. 2017, 8. [CrossRef]

150. Bi, S.; Sourjik, V. Stimulus Sensing and Signal Processing in Bacterial Chemotaxis. Curr. Opin. Microbiol. 2018, 45, 22-29. [CrossRef]

151. Inoue, K.; Ono, H.; Abe-Yoshizumi, R.; Yoshizawa, S.; Ito, H.; Kogure, K.; Kandori, H. A Light-Driven Sodium Ion Pump in Marine Bacteria. Nat. Commun. 2013, 4, 1678. [CrossRef]

152. Skopintsev, P.; Ehrenberg, D.; Weinert, T.; James, D.; Kar, R.K.; Johnson, P.J.M.; Ozerov, D.; Furrer, A.; Martiel, I.; Dworkowski, F; et al. Femtosecond-to-Millisecond Structural Changes in a Light-Driven Sodium Pump. Nature 2020, 583, 314-318. [CrossRef] [PubMed]

153. Blee, J.A.; Roberts, I.S.; Waigh, T.A. Membrane Potentials, Oxidative Stress and the Dispersal Response of Bacterial Biofilms to 405 nm Light. Phys. Biol. 2020, 17, 036001. [CrossRef] [PubMed]

154. Terai, T.; Nagano, T. Fluorescent Probes for Bioimaging Applications. Curr. Opin. Chem. Biol. 2008, 12, 515-521. [CrossRef]

155. Fu, Y.; Finney, N.S. Small-Molecule Fluorescent Probes and their Design. RSC Adv. 2018, 8, 29051-29061. [CrossRef]

156. Phanphak, S.; Georgiades, P.; Li, R.; King, J.; Roberts, I.S.; Waigh, T.A. Super-Resolution Fluorescence Microscopy Study of the Production of K1 Capsules by Escherichia coli: Evidence for the Differential Distribution of the Capsule at the Poles and the Equator of the Cell. Langmuir 2019, 35, 5635-5646. [CrossRef] [PubMed]

157. Caglar, M.; Pandya, R.; Xiao, J.; Foster, S.K.; Divitini, G.; Chen, R.Y.S.; Greenham, N.C.; Franze, K.; Rao, A.; Keyser, U.F. All-Optical Detection of Neuronal Membrane Depolarization in Live Cells Using Colloidal Quantum Dots. Nano Lett. 2019, 19, 8539-8549. [CrossRef] [PubMed]

158. Gong, H.; Liao, M.; Hu, X.; Fa, K.; Phanphak, S.; Ciumac, D.; Hollowell, P.; Shen, K.; Clifton, L.A.; Campana, M.; et al. Aggregated Amphiphilic Antimicrobial Peptides Embedded in Bacterial Membranes. ACS Appl. Mater. Interfaces 2020, 12, 44420-44432. [CrossRef] [PubMed]

159. Park, S.-H.; Kwon, N.; Lee, J.-H.; Yoon, J.; Shin, I. Synthetic Ratiometric Fluorescent Probes for Detection of Ions. Chem. Soc. Rev. 2020, 49, 143-179. [CrossRef] [PubMed]

160. Shashkova, S.; Leake, M.C. Single-Molecule Fluorescence Microscopy Review: Shedding New Light on Old Problems. Biosci. Rep. 2017, 37. [CrossRef]

161. Sözer, E.B.; Pocetti, C.F.; Vernier, P.T. Transport of Charged Small Molecules after Electropermeabilization-Drift and Diffusion. BMC Biophys. 2018, 11, 4. [CrossRef] [PubMed]

162. Kapanidis, A.N.; Uphoff, S.; Stracy, M. Understanding Protein Mobility in Bacteria by Tracking Single Molecules. J. Mol. Biol. 2018, 430, 4443-4455. [CrossRef] [PubMed]

163. Li, R.; Georgiades, P.; Cox, H.; Phanphak, S.; Roberts, I.S.; Waigh, T.A.; Lu, J.R. Quenched Stochastic Optical Reconstruction Microscopy (qSTORM) with Graphene Oxide. Sci. Rep. 2018, 8, 16928. [CrossRef] [PubMed] 